\title{
The Role of Hadley Circulation and Lapse-Rate Changes for the Future European Summer Climate ${ }^{\mathscr{O}}$
}

\author{
Roman Brogli, Nico Kröner, Silje Lund Sørland, DANiel LÜthi, ${ }^{a}$ AND CHristoph SchÄr \\ Institute for Atmospheric and Climate Science, ETH Zürich, Zurich, Switzerland
}

(Manuscript received 2 July 2018, in final form 8 October 2018)

\begin{abstract}
By the end of the century, climate projections for southern Europe exhibit an enhanced near-surface summer warming in response to greenhouse gas emissions, which is known as the Mediterranean amplification. Possible causes for this amplified warming signal include a poleward Hadley cell expansion as well as tropospheric lapse-rate changes. In this work, regional climate model (RCM) simulations driven by three different global climate models (GCMs) are performed, representing the RCP8.5 emission scenario. For every downscaled GCM, the climate change signal over Europe is separated into five contributions by modifying the lateral boundary conditions of the RCM. This simulation strategy is related to the pseudoglobal warming method. The results show that a poleward expansion of the Hadley cell is of minor importance for the Mediterranean amplification. During summer, the simulated Hadley circulation is weak, and projections show no distinct expansion in the European sector. The north-south contrast in lapse-rate changes is suggested as the most important factor causing the Mediterranean amplification. Lapse-rate changes are projected throughout Europe, but are weaker over the Mediterranean than over northern Europe (around $0.15 \mathrm{vs} 0.3 \mathrm{~K} \mathrm{~km}^{-1}$ by the end of the century). The weaker lapse-rate changes result in a strong near-surface summer warming over the Mediterranean, since the upper-tropospheric warming is of similar magnitude throughout Europe. The differing lapse-rate changes can be understood as a thermodynamic response to lower-tropospheric humidity contrasts.
\end{abstract}

\section{Introduction}

The continued increase of greenhouse gas emissions is projected to lead to an additional warming of Earth's atmosphere compared to what is already observed (Stocker et al. 2013). The impact of this warming on regional scales is subject to large uncertainties (Hawkins and Sutton 2009), but many models agree on severe consequences for the Mediterranean (MED) summer season (Schär et al. 2004; Ulbrich et al. 2006; Giorgi and Lionello 2008; Seager et al. 2014; Bladé et al. 2012). An enhanced near-surface summer warming and drying in the Mediterranean compared to the rest of Europe is

Supplemental information related to this paper is available at the Journals Online website: https://doi.org/10.1175/JCLID-18-0431.s1.

${ }^{\mathrm{a}}$ Deceased.

Corresponding author: Roman Brogli, roman.brogli@env. ethz.ch projected by the end of the century. This north-south warming gradient is commonly referred to as the Mediterranean amplification. The Mediterranean amplification is expected to have socioeconomic (Lorenzo et al. 2016) and ecological (Anderegg et al. 2013) impacts, for example, due to more frequent heat waves (Fischer and Schär 2010) or water scarcity (Seager et al. 2014; Gudmundsson et al. 2017). The Mediterranean has therefore been identified as a "hot spot" of climate change (Giorgi 2006). Yet, the causes for the Mediterranean amplification remain debated (Kröner et al. 2017)

The projected poleward expansion of the Hadley cell (Lu et al. 2007; Birner et al. 2014; Lucas et al. 2014; Heffernan 2016) is thought to be a possible cause of the Mediterranean amplification. The poleward expansion of the Hadley cell would shift the subsidence zone related to the subtropical dry zone northward in Europe, leading to an enhanced drying and warming of the Mediterranean (Scheff and Frierson 2012; Hoerling et al. 2012). This simple view has been challenged by studies on a global scale, noting that the subtropical 
drying is mainly a feature found over oceans (Schmidt and Grise 2017) and present even in the absence of a Hadley cell expansion (He and Soden 2017).

Lapse-rate changes have been shown to contribute to the Mediterranean amplification (Kröner et al. 2017). The projected future lapse rates are characterized by a stronger upper-level warming in comparison to the ground (Byrne and O'Gorman 2013a). This is caused by moist adiabatic vertical mixing that maintains the thermal stratification close to a moist adiabat in summer over continental regions (Schneider 2007). As the atmosphere warms, it can carry more moisture because of the Clausius-Clapeyron relation (Allen and Ingram 2002; Held and Soden 2006). During moist adiabatic vertical motions, more latent heat can be released into the upper troposphere, which leads to the enhanced warming (Schneider 2007). This process increases the atmosphere's dry static stability, and its influence on the equilibrium climate sensitivity is referred to as lapserate feedback (Bony et al. 2006). Regionally different lapse-rate changes can influence the spatial pattern of climate change. Most notably, differing lapse-rate changes have been suggested as a driver of the land-sea contrast of warming (Byrne and O'Gorman 2013a,b; Sherwood and $\mathrm{Fu}$ 2014). The moisture contrast between land and sea leads to different lapse-rate changes in a way that, if upper-level warming is uniform, the temperature over land warms more than over ocean (Joshi et al. 2008; Byrne and O'Gorman 2018). However, it is less clear how lapse-rate changes influence the Mediterranean amplification.

Kröner et al. (2017) showed that the Mediterranean amplification could not be invoked by homogeneously warming a present-day climate simulation, even with fully interactive subcontinental-scale climate feedbacks. Rowell and Jones (2006) explain the enhanced summer drying in the Mediterranean partly by a soilmoisture-precipitation feedback (Seneviratne et al. 2010), yet they find that the direct influence of the warming is more important than the soil-moisture feedback.

In this study, we separate the climate change signal over Europe into five contributing changes and investigate their relative importance for the Mediterranean warming amplification. To do so, we use the pseudo-global warming (PGW) method, which has been developed and applied extensively in previous studies (Schär et al. 1996; Kawase et al. 2009; Rasmussen et al. 2011, 2014; Yoshikane et al. 2012; Lackmann 2013; Kröner et al. 2017; Prein et al. 2017a,b; Singh et al. 2018; Mahoney et al. 2018). The approach presented in Kröner et al. (2017, manuscript submitted to Nat. Sci. Rep., hereafter KLS) is used and extended. Thereby, the lateral boundary conditions of a regional climate simulation are modified with different contributions to climate change, which originate from a global climate simulation. The PGW method is often applied using only a single global climate model (GCM) simulation, which has the drawback that no assessment of largescale uncertainties is possible (Nishizawa et al. 2018). This is also the case in Kröner et al. (2017) and KLS. We overcome this shortcoming by constructing an ensemble that consists of PGW simulations using the same regional climate model, but it is driven by three different GCMs.

This article is structured as follows: Section 2 introduces the methods, including a description of the numerical models and a short description of the PGW experiments. Details regarding the PGW experiments can be found in appendix A. In section 3, the simulation results are presented and discussed in detail. Section 4 contains a summary and concluding remarks. Furthermore, appendix B contains a list of the symbols used. In the main article, we restrict the attention to the summer season, but the supplemental material includes figures for the winter season.

\section{Methods}

\section{a. $R C M$}

We use the regional climate model (RCM) of the Consortium for Small-Scale Modeling (COSMO) in climate mode (CCLM), where the version CCLM4.8 clm17 (Rockel et al. 2008) is used for consistency with previous studies. The COSMO model is a nonhydrostatic, fully compressible limited-area model using a rotated longitude-latitude grid (Steppeler et al. 2003; Doms et al. 2011). The simulation domain follows the European branch of the World Climate Research Program Coordinated Regional Downscaling Experiment (EURO-CORDEX) framework (Jacob et al. 2014; Kotlarski et al. 2014), where the domain approximately spans $27^{\circ}-72^{\circ} \mathrm{N}, 33^{\circ} \mathrm{W}-45^{\circ} \mathrm{E}$, covering the pan-European continent. The horizontal resolution is $0.44^{\circ}(\sim 50 \mathrm{~km})$ and we use 40 stretched vertical levels between $20 \mathrm{~m}$ and $22.7 \mathrm{~km}$.

\section{b. Global-driving simulations}

The lateral boundary conditions for CCLM are provided by three different GCMs. The driving GCMs are HadGEM2-ES, MPI-ESM-LR, and CNRM-CM5. ${ }^{1}$

\footnotetext{
${ }^{1}$ A technical error has been reported for the CNRM-CM5 data we use for downscaling. See supplemental material for more information.
} 
TABLE 1. List of global simulations used for driving the regional simulations, including the model name, the horizontal and vertical resolutions, and a reference for further information. If two numbers are shown for the horizontal resolution, they refer to the grid spacing for longitude and latitude at the equator, respectively.

\begin{tabular}{lccc}
\hline \hline Model name & Horizontal resolution $(\mathrm{km})$ & Vertical levels & Reference \\
\hline HadGEM2-ES & $210 \times 140$ & 38 & Martin et al. (2011) \\
MPI-ESM-LR & 210 & 47 & Stevens et al. (2013) \\
CNRM-CM5 & 160 & 31 & Voldoire et al. (2013) \\
\hline
\end{tabular}

Details and references for the driving GCMs are shown in Table 1. Each GCM is downscaled for a historical period (1950-2005) and for a future scenario (2006-99) assuming the greenhouse gas concentration given by the representative concentration pathway (RCP) 8.5 (RCP8.5; Moss et al. 2010; Riahi et al. 2011). For the entire time period simulated, the aerosol climatology from Tanré et al. (1984) is used. Soil-moisture is initialized from a spinup simulation. For the analysis of climate change, we compare the 30 -yr historical control period from 1971 to 2000 (CTRL) to the scenario period taken from 2070 to 2099 (SCEN). In the PGW experiments (see next section), we only simulate the time slices of CTRL and SCEN, where we use one year as spinup prior to the analysis period in all PGW simulations.

\section{c. Separation of climate change drivers}

To separate and quantify contributions to the total climate change signal, for each GCM, we perform PGW simulations (Kröner et al. 2017) based on the CTRL and SCEN simulations and apply the sequential factor separation method (Schär and Kröner 2017). This means that CCLM's lateral boundaries are modified by adding or removing a part of the climate change signal simulated by the GCMs and analyzing the effect of this specific contribution in the RCM simulations. Following Kröner et al. (2017), we add a modification to the lateral boundaries of a simulation of the CTRL period, and additionally, we remove the same modification from the lateral boundaries of a SCEN simulation. This means that we have two ways of quantifying the effect of every contribution to climate change. We analyze the average effect of the two approaches. Through the mentioned modifications, we separate the total change between SCEN and CTRL into five different contributions with increasing complexity. For these five contributing changes, the separation requires 10 simulations per GCM, yielding a total of 30 simulations, each with a duration of 31 years. Figure 1 provides an overview of the simulations and the separated contributions to climate change. In the following subsections, a qualitative description of the separated contributions is presented. A description of the technical details of the simulations is presented in appendix A.

\section{1) Thermodynamic CHAnge}

The first contribution to climate change we aim to quantify is referred to as thermodynamic change (TD). TD represents the expected effects from changes in future temperature and the associated moisture content, following the Clausius-Clapeyron relation [i.e., increase of $\left.6 \%-7 \%(\mathrm{~K})^{-1}\right]$. There are no prescribed changes in the large-scale dynamics or lapse rates at the lateral boundaries, and the hydrostatic and dynamic balances are unchanged (Schär et al. 1996). We achieve this by modifying the lateral boundaries using a homogeneous temperature difference $(\Delta T=\mathrm{SCEN}-\mathrm{CTRL})$ independent of location and height (see Fig. 1). Changes in greenhouse gas concentrations are included. As mentioned, we add the homogeneous temperature modification to a CTRL simulation and subtract from a SCEN simulation. We denote the modified simulations as $\mathrm{CTRL}_{\Delta T}$ and $\mathrm{SCEN}_{\Delta T}$ (see Fig. 1). TD is subsequently quantified as the average difference between $\mathrm{CTRL}_{\Delta T}-\mathrm{CTRL}$ and SCEN $-\mathrm{SCEN}_{\Delta \mathrm{T}}$.

\section{2) Mean lapse-Rate Change}

The second contribution is the mean lapse-rate change (LR). LR represents the effect of domain-mean changes in the atmospheric stratification. We modify the lateral boundaries of the parent simulations (i.e., CTRL or SCEN) with the domain-mean temperature and humidity change at every height level separately $[\Delta T(z)$ instead of $\Delta T$, yielding the $\operatorname{CTRL}_{\Delta T(z)}$ and $\operatorname{SCEN}_{\Delta T(z)}$ simulations as shown by Fig. 1]. We subsequently quantify LR by comparing the simulations with a height-dependent temperature modification $\Delta T(z)$ to those with a homogeneous modification $\Delta T$. As a result, LR shows the additional impact of changing the domain-mean lapse rate at the lateral boundaries.

\section{3) Meridional CHANGE}

Further increasing the complexity of the PGW simulations allows us to quantify the meridional change (MC). MC includes two important dynamically linked processes. First, meridional circulation changes on a seasonal time scale are simulated (such as a northward shift of the Hadley cell). Second, the meridional gradient 


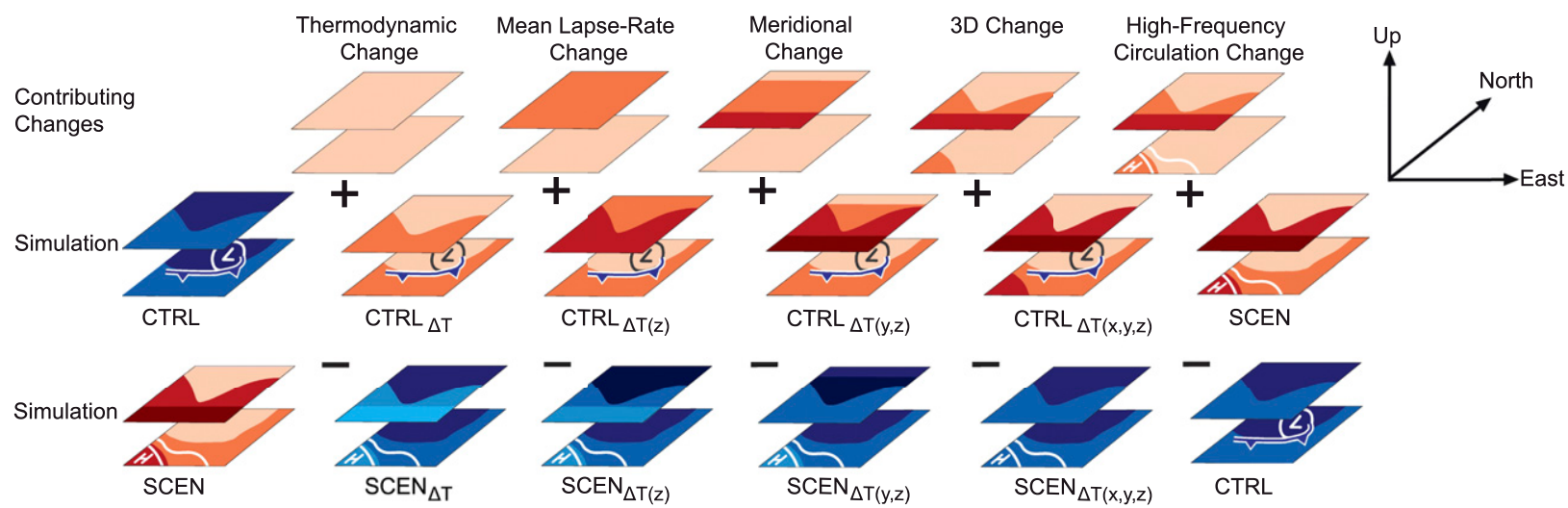

FIG. 1. Different RCM simulations with the required modifications to separate contributions to the total climate change signal. (top) Contributions to climate change used to modify the lateral boundary fields provided by a GCM. For every contribution, the respective panel shows the temperature change on a lower and an upper model level. After modifying the lateral boundaries with the five contributions shown in the top row, we can analyze their relative impact in the RCM simulations. (middle) Simulations based on a warming of the CTRL simulation. Each panel shows the approximate effect every modification has on the GCM-derived boundary field that is used to drive CCLM. The respective name for each simulation is indicated. (bottom) Simulations based on a cooling of the SCEN simulation. Red colors denote warmer temperatures relative to CTRL; blue colors show cooler temperatures relative to SCEN. For both the warming and cooling experiments, the low and high pressure systems are schematically shown to indicate which simulations are provided with the same sequence of baroclinic eddies at the lateral boundaries. (left to right) The contributing changes are added (removed) step by step to the CTRL (SCEN) simulation until we arrive at the SCEN (CTRL) simulation. Note that for simplicity, only changes in temperature at a specific time step are shown here, even though additional changes in other model quantities are conducted in the PGW simulations and the modifications include a representation of the seasonal cycle (see appendix A for more details).

of lapse-rate changes (Fig. 11) is included at the lateral boundaries. This is achieved by modifying the parent simulations with meridional and vertical temperature $\Delta T(y, z)$ and humidity-change gradients and adapting the wind according to the thermal wind balance (Fig. 1). $\mathrm{MC}$ is determined by comparing the modified simulations to the simulations used to quantify LR (see appendix A). Note that the meridional change was not included in Kröner et al. (2017) and KLS and is used for the first time in a pseudo-global warming framework in this study.

\section{4) $3 \mathrm{D}$ CHANGE}

A last set of PGW simulations is performed to assess the $3 \mathrm{D}$ change. The $3 \mathrm{D}$ change $(3 \mathrm{D})$ represents the quasi-stationary circulation and associated temperature and humidity changes on seasonal time scales. The derived quasi-stationary large-scale circulation patterns are closely related to classical circulation patterns (some resembling the North Atlantic Oscillation or the Scandinavian pattern). To represent the mean seasonal changes in circulation as simulated by the GCM considered, and temperature variations consistent with the thermal wind balance, the parent simulations are modified by temperature and wind change gradients in all spatial dimensions $\Delta T(x, y, z)$ [which yields the CTRL $\mathrm{CT}_{\Delta(x, y, z)}$ and $\operatorname{SCEN}_{\Delta T(x, y, z)}$ simulations as shown by Fig. 1]. During the analysis of our simulations, in order to quantify 3D, we compare the simulations targeting 3D to the simulations targeting $\mathrm{MC}$ (appendix A). Therefore, the results we analyze for 3D do not include the mean meridional changes, as these are included with MC, but only the additional impact of the $3 \mathrm{D}$ processes described above. Similarly, the impact of 3D does not include mean thermodynamic or lapse-rate changes, as the latter are included with TD and LR.

\section{5) High-FREQuenCy CiRCUlation CHANGE}

The last contribution to climate change that we can quantify with our approach is referred to as high-frequency circulation change (HF). However, no additional simulations are needed to quantify HF. HF rather includes all differences between the most complex PGW simulations, including the $3 \mathrm{D}$ change described in the previous section, and the SCEN or CTRL simulations (residual). The most prominent contribution to $\mathrm{HF}$ stems from changes in baroclinic eddies and the associated weather systems (Fig. 1). In essence, the pairs of simulations we compare to quantify HF (e.g., SCEN and $\left.\operatorname{CTRL}_{\Delta T(x, y, z)}\right)$ are very similar. The main difference is the sequence of baroclinic eddies provided at the lateral boundaries, which stem from either CTRL or SCEN. In the interior of the domain, however, the dynamics are free and the synoptic systems adjust to the large-scale baroclinic structure. 


\section{6) Total change}

By design of our experiments, the total climate change (TOT) is given by TOT $=$ SCEN - CTRL, which is equal to the sum of the five separated contributions to climate change (for more details, see Schär and Kröner 2017):

$$
\mathrm{TOT}=\mathrm{TD}+\mathrm{LR}+\mathrm{MC}+3 \mathrm{D}+\mathrm{HF} .
$$

\section{d. Hadley cell diagnostics}

To investigate Hadley circulation changes, we diagnose the Hadley cell strength and extent in the vicinity of Europe in the three driving GCMs (Table 1). Commonly, the global zonal-mean meridional mass streamfunction

$$
\Psi=2 \pi a \cos (\phi) g^{-1} \int_{0}^{p} \bar{v} d p,
$$

is used for this task (Oort and Yienger 1996; Lu et al. 2007; $\mathrm{Hu}$ and $\mathrm{Fu}$ 2007; D'Agostino and Lionello 2017; D'Agostino et al. 2017). Here, $a$ is the Earth radius, $\phi$ is latitude, $g$ is gravitational acceleration, $p$ is pressure, $\bar{v}$ is the mean meridional wind component, and $\Psi$ is a measure of the amount and the direction of mass transport above the altitude with pressure $p$. In the Northern Hemisphere, a poleward mass transport within the upper branch of the Hadley cell results in a positive $\Psi$ in the upper troposphere. The Hadley cell edge is located at the latitude where $\Psi=0$ (i.e., the latitude where the upper-tropospheric mass transport is not poleward anymore).

However, defining $\Psi$ on a regional scale between two arbitrary longitude bands $\lambda_{1}$ and $\lambda_{2}$ can be problematic since $\Psi$ relies on the assumption that $\partial v / \partial y=0$, which is only true in the global zonal mean (Studholme and Gulev 2018). This problem can be resolved by defining an alternative form of the streamfunction as follows (Zhang and Wang 2013; Nguyen et al. 2018; Studholme and Gulev 2018):

$$
\Psi_{\chi}=2 \pi a \cos (\phi) g^{-1} \int_{0}^{p}\left[v_{\chi}\right]_{\lambda_{1}}^{\lambda_{2}} d p
$$

Here, $\left[v_{\chi}\right]_{\lambda_{1}}^{\lambda_{2}}$ is the irrotational (or divergent) component of the Helmholtz-decomposed wind vector field between the two longitudes $\lambda_{1}$ and $\lambda_{2}$. We compute $v_{\chi}$ using the windspharm Python package (Dawson 2016). We use $\Psi_{X}$ averaged between 700 and $300 \mathrm{hPa}$ and between $10^{\circ} \mathrm{W}$ and $35^{\circ} \mathrm{E}$ as a measure for Hadley cell strength at a given latitude in the European sector. We take the northern Hadley cell edge to be at the latitude where $\Psi_{\chi}=0$ north of the tropics (also averaged between 700 and $300 \mathrm{hPa}$ and $10^{\circ} \mathrm{W}$ and $\left.35^{\circ} \mathrm{E}\right)$.

\section{Results and discussion}

\section{a. Separated contributions to climate change}

Figure 2 shows the anomaly of the summer 2-m temperature change over Europe from the CCLM simulations driven by the three GCMs, HadGEM2-ES, MPI-ESM-LR, and CNRM-CM5. Each of the five separated contributing changes (section 2c) is shown, along with the total change (TOT $=$ SCEN - CTRL). As mentioned in section $2 \mathrm{c}$, we average two approaches for quantifying the five contributing changes shown in Fig. 2, one approach based on a warming of a historical CTRL simulation and another based on a cooling of a future SCEN simulation. As also found by Kröner et al. (2017), the individual results of the two approaches agree very well (see Figs. S1-S3 in the online supplemental material), suggesting that the separation is robust independent of the background climate variability. In the following, we discuss the different contributions in more detail.

\section{1) Total ChAnge}

The spatial pattern of total temperature change is similar in the three simulations; however, there is a spread in the magnitude (see Fig. 2, bottom row). The simulations driven by HadGEM2-ES, MPI-ESM-LR, and CNRM-CM5 show a domain-averaged warming of $5.3,3.5$, and $3.3 \mathrm{~K}$, respectively.

The Mediterranean amplification is evident in all three simulations over land areas. The north-south warming contrast is largest in the simulation driven by MPIESM-LR and is around $2 \mathrm{~K}$ on average. The north-south warming contrast is of similar magnitude for the HadGEM2-ES- and CNRM-CM5-driven simulations $(\sim 1-1.5 \mathrm{~K})$, despite the large difference in mean warming (see Fig. 2). The area exhibiting a positive warming anomaly is, however, larger for HadGEM2-ES compared to CNRM-CM5. The temperature change over the sea surface of the Mediterranean is remarkably close to the domain-mean warming in all three simulations.

\section{2) THERMODYNAMic CHANGE}

The contribution from the thermodynamic change explains the largest fraction of the total warming (Fig. 2). The domain-averaged warming is $5,3.9$, and $3 \mathrm{~K}$ for HadGEM2-ES, MPI-ESM-LR, and CNRM-CM5, respectively. Hence, TD shows a similar domain average warming as TOT. However, consistent with Kröner et al. (2017), we find no amplified warming in the Mediterranean 

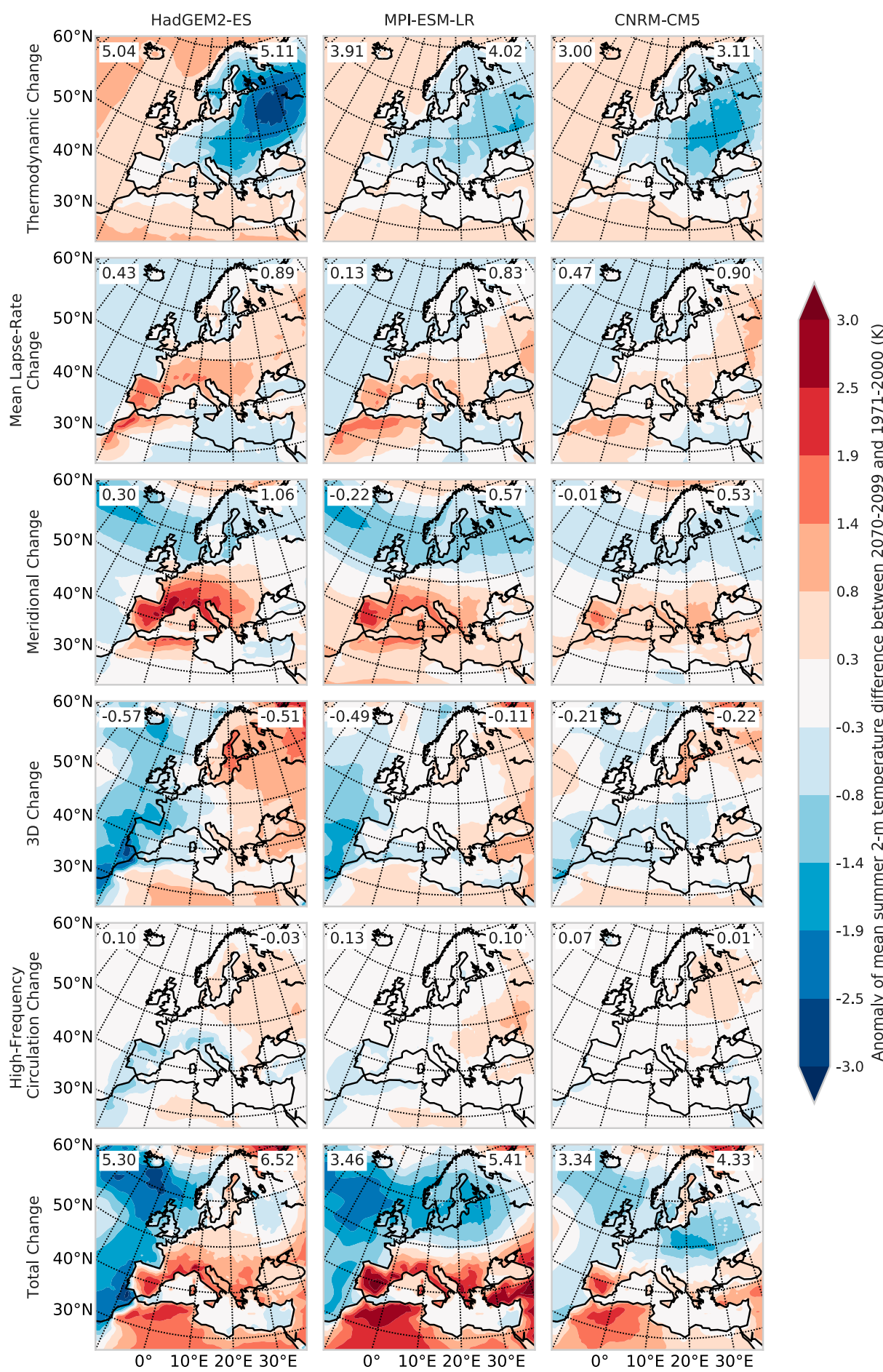

FIG. 2. Separation of the mean summer 2-m temperature change anomaly into five contributions to climate change in regional simulations with the CCLM model. The temperature difference is between the SCEN (2070-99) and CTRL (1971-2000) period assuming the RCP8.5 scenario. The colors show the anomaly of the 2-m temperature change (i.e., every grid point's deviation from the domain-mean temperature change). In each panel, the domain-average warming $(\mathrm{K})$ is given by the number in the upper-left corner, while the average warming over MED land grid points (between $30^{\circ}$ and $44^{\circ} \mathrm{N}$ ) is shown in the upper right. The CCLM simulations are driven by the GCMs (left) HadGEM2-ES, (middle) MPI-ESM-LR, and (right) CNRM-CM5. (top five rows) The separated contributions to climate change. The five contributions are (first row) TD, (second row) LR, (third row) MC, (fourth row) 3D, and (fifth row) HF. (bottom row) The total climate change signal (SCEN - CTRL), which is the sum of the five contributions in the above rows. Note that negative values in the plot represent a below-domain-average warming and not a cooling in absolute terms. 
in any simulation. Rather, there is a reduced warming over continental northeast Europe, especially in the HadGEM2-ES- and CNRM-CM5-driven simulations. In this region, the low-level atmospheric moisture availability is increasing in the two simulations. The sensible heat flux decreases and the latent heat flux increases (not shown). Thus, the reduced warming can be explained by a negative feedback on temperature by the increased moisture content.

\section{3) Mean lapse-Rate change}

Even though the mean lapse-rate change only has a small effect on the domain-mean warming $(0.1-0.5 \mathrm{~K})$, it introduces an additional warming over the continent (Fig. 2). The additional warming is strongest over the Mediterranean $(\sim 0.9 \mathrm{~K})$ in all simulations. The results suggest that the mean lapse-rate change is contributing to the Mediterranean amplification and confirm the findings of Kröner et al. (2017). The stronger upper-level warming introduced at the model boundary induces a warming of the lower troposphere in southern Europe (Fig. 2).

\section{4) Meridional change}

The meridional change induces a very pronounced positive warming anomaly in the Mediterranean in all simulations in the absence of an additional domain mean warming. A clear north-south warming gradient is evident, also because of a negative warming anomaly in northern Europe (Fig. 2). The spatial warming difference amounts up to $3-4 \mathrm{~K}$ in certain areas. In our decomposition, the meridional change is the single most important contribution to the Mediterranean amplification. Possible reasons why the meridional change induces a positive Mediterranean warming anomaly are further discussed in section $3 \mathrm{~b}$.

\section{5) 3D CHANGE}

The main impact of the 3D change is a cooling over oceanic regions or regions in close proximity to the ocean (Fig. 2). The 3D effect is necessary to explain parts of the mainly zonally oriented land-sea contrast in warming over the domain. The $3 \mathrm{D}$ change does not further contribute to the Mediterranean amplification but rather weakens the north-south warming gradient and also weakens the domain-mean warming both by $0.1-0.6 \mathrm{~K}$.

\section{6) High-FREQUenCy CiRCULATiOn CHANGE}

The impact of the high-frequency circulation change on 2-m temperature is very small in all three simulations $(\sim 0.1 \mathrm{~K})$. Consistent with KLS, we find that changes in the sequence of baroclinic eddies entering the domain are not important to explain the mean summer near-surface temperature change over Europe in our simulations. For the summer season, Seager et al. (2014) also found a relatively small role of transient eddy changes compared to mean flow and mean moisture changes while analyzing the Mediterranean moisture budget.

\section{7) Precipitation changes}

The main focus of this work lies on the Mediterranean warming amplification, which will be more thoroughly analyzed and discussed in the following sections. Yet, along with the Mediterranean amplification, an enhanced drying is projected. For completeness, we show the total change in precipitation along with the five separated contributions to the total change in Fig. 3. The most important observations from Fig. 3 can be summarized as follows: A summer drying over the Mediterranean for the total change is evident. The contribution of the thermodynamic change leads to a moistening of the domain because of the Clausius-Clapeyron relation and relatively high sea surface temperatures. Similar to the temperature change, the mean lapse-rate change and the meridional change seem to be crucial contributions causing the Mediterranean summer drying.

\section{b. Further analysis}

The results presented in Fig. 2 show that the meridional change yields the most important contribution to the Mediterranean warming amplification seen in the total change. Thus, in the following, we present a more detailed analysis of two contributing effects to the meridional change that could be responsible for the warming amplification, namely, the Hadley cell expansion and the meridional distribution of lapse-rate changes. While not completely independent, these two factors are analyzed separately. The analysis of the Hadley cell expansion is based on direct GCM output since large parts of the Hadley circulation are located outside of the regional model domain. The lapse-rate changes are evaluated using regional model data. In addition to the analysis of the meridional change presented below, some peculiarities of the mean lapse-rate change are discussed in the supplemental material.

\section{1) HADLEy CELL EXPANSION}

The annual cycle of Hadley circulation strength and the latitude of the northern edge of the Hadley cell in the European sector from the GCMs are shown in Fig. 4. Both the strength and the extent of the Hadley cell are based on $\Psi_{\chi}$, described in section 2d. Additionally, a vertical cross section of the summer mean $\Psi_{\chi}$ is shown 

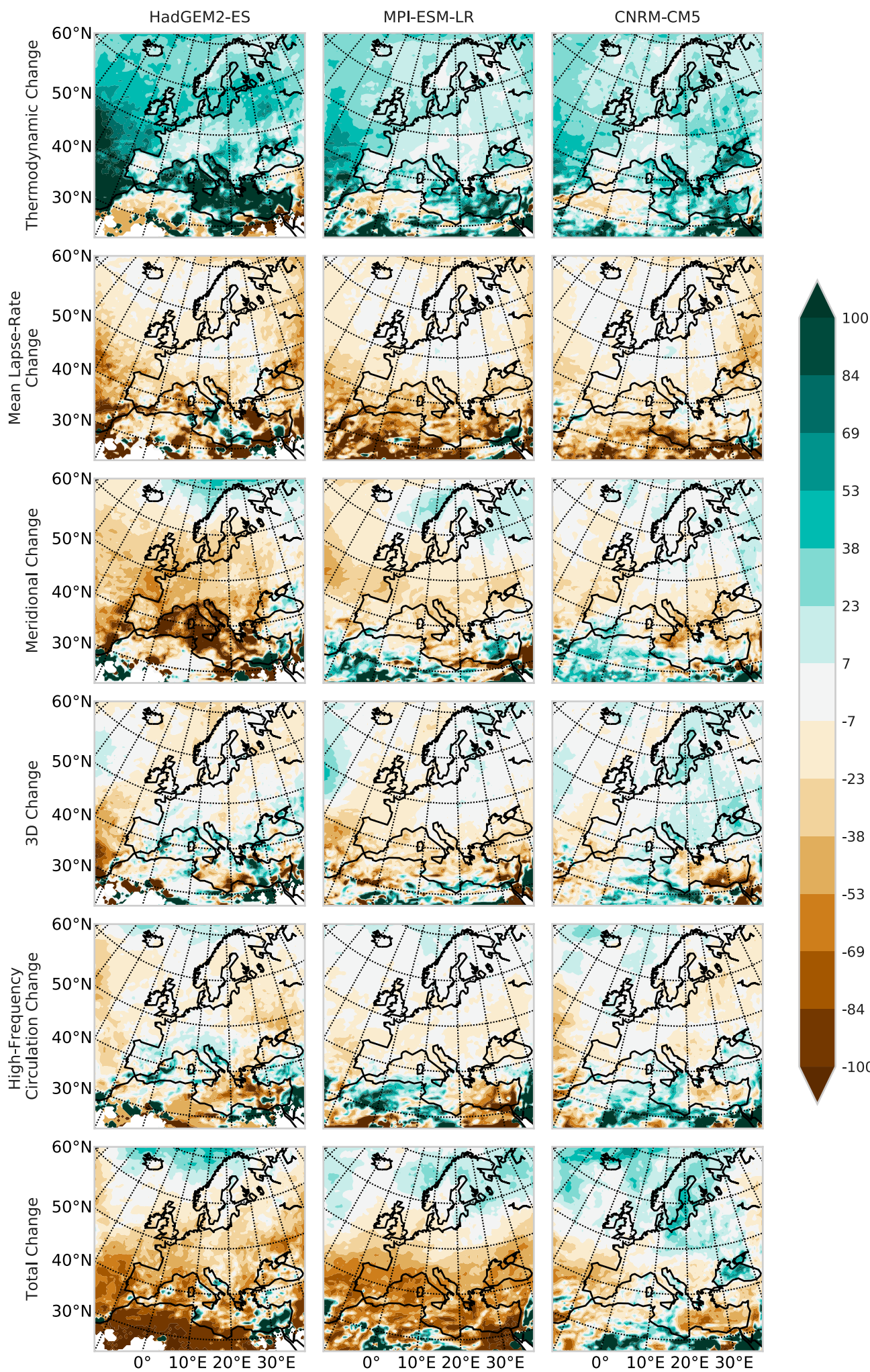

FIG. 3. As in Fig. 2, but for mean summer precipitation changes (\%). Note that the high values in the far southern part of the domain are caused by the very small climatological precipitation values. 

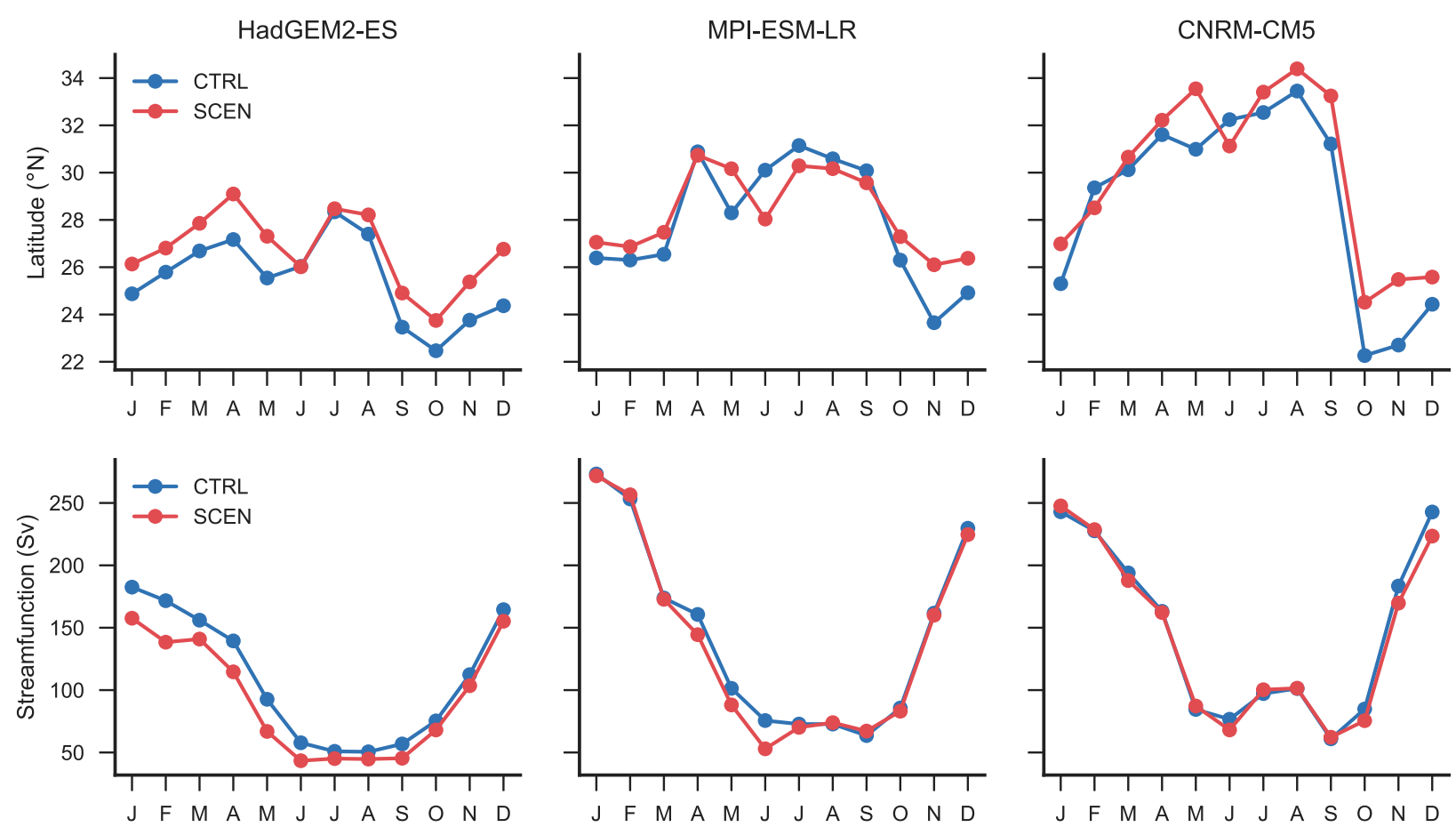

FIG. 4. Properties of the northern Hadley circulation within the longitudes containing Europe $\left(10^{\circ} \mathrm{W}-35^{\circ} \mathrm{E}\right)$ in the (left) HadGEM2-ES, (middle) MPI-ESM-LR, and (right) CNRM-CM5 global simulations. (top) Monthly mean Hadley cell edge latitude given by $\Psi_{\chi}=0$, averaged between 700 and $300 \mathrm{hPa}$ (see section 2d). The mean latitude during the historical CTRL (1971-2000) period is shown in blue and the latitude during the future SCEN (2070-99) period is shown in red. (bottom) Maximum strength of the Hadley circulation south of Europe given by the maximum of $\Psi_{\chi}$ north of the equator, averaged between 700 and $300 \mathrm{hPa}\left(\mathrm{Sv} ; 1 \mathrm{~Sv}=10^{9} \mathrm{~kg} \mathrm{~s}^{-1}\right)$. The blue line shows the CTRL period and the red line the SCEN period.

in Fig. 5. Figure 4 in comparison with Fig. 2 allows us to investigate the relation between the northward expansion of the Hadley cell and the Mediterranean amplification.

In the European sector, the annual cycle of the Hadley circulation strength shows a minimum in summer (Fig. 4, bottom panels). The zonal-mean Hadley circulation is weaker in summer than in winter by about $80 \%$ in all three simulations in both the CTRL and the SCEN periods. Hence, these results suggest that the Hadley circulation has a weaker impact on the European summer climate compared to the winter climate.

Regarding the latitude of the northern Hadley cell edge, we generally diagnose that the edge latitude is located between $26^{\circ}$ and $34^{\circ} \mathrm{N}$ in summer, in both CTRL and SCEN, which is farther south than many of the areas where the Mediterranean amplification is observed in the simulations (Fig. 2). However, the Hadley cell edge considered is a mean value over the troposphere and the Hadley cell edge can be located farther north at lower levels (Fig. 5).

The three simulations do not consistently show a poleward expansion of the Hadley cell edge in summer by the end of the century (Figs. 4, 5), while all three
GCMs show a poleward expansion in autumn/winter (Fig. 4). A very similar result has been found on a global scale by D'Agostino et al. (2017), using a larger model ensemble. In addition, the simulated changes of the Hadley cell edge do not correlate well with the simulated strength of the Mediterranean amplification. In HadGEM2-ES, we find no change of the Hadley cell extent in June and July and a weak poleward expansion in August, while an expansion of the Hadley cell is evident in spring (Fig. 4), reaching a similar latitude as in summer, yet there is no pronounced Mediterranean amplification in spring (not shown). In MPI-ESM-LR, an equatorward contraction of the Hadley cell in the vicinity of Europe is found during summer. Yet, the MPI-ESM-LR-driven RCM simulation shows the strongest Mediterranean amplification (Fig. 2). The CNRMCM5 simulation exhibits a poleward expansion of the Hadley cell in two out of the three summer months. Furthermore, the Hadley circulation is the strongest among the three simulations during summer and reaches furthest north in CNRM-CM5 (Figs. 4, 5). Still, the Mediterranean amplification is comparably weak in the CNRM-CM5-driven RCM simulation, especially if only analyzing the meridional change (Fig. 2). 

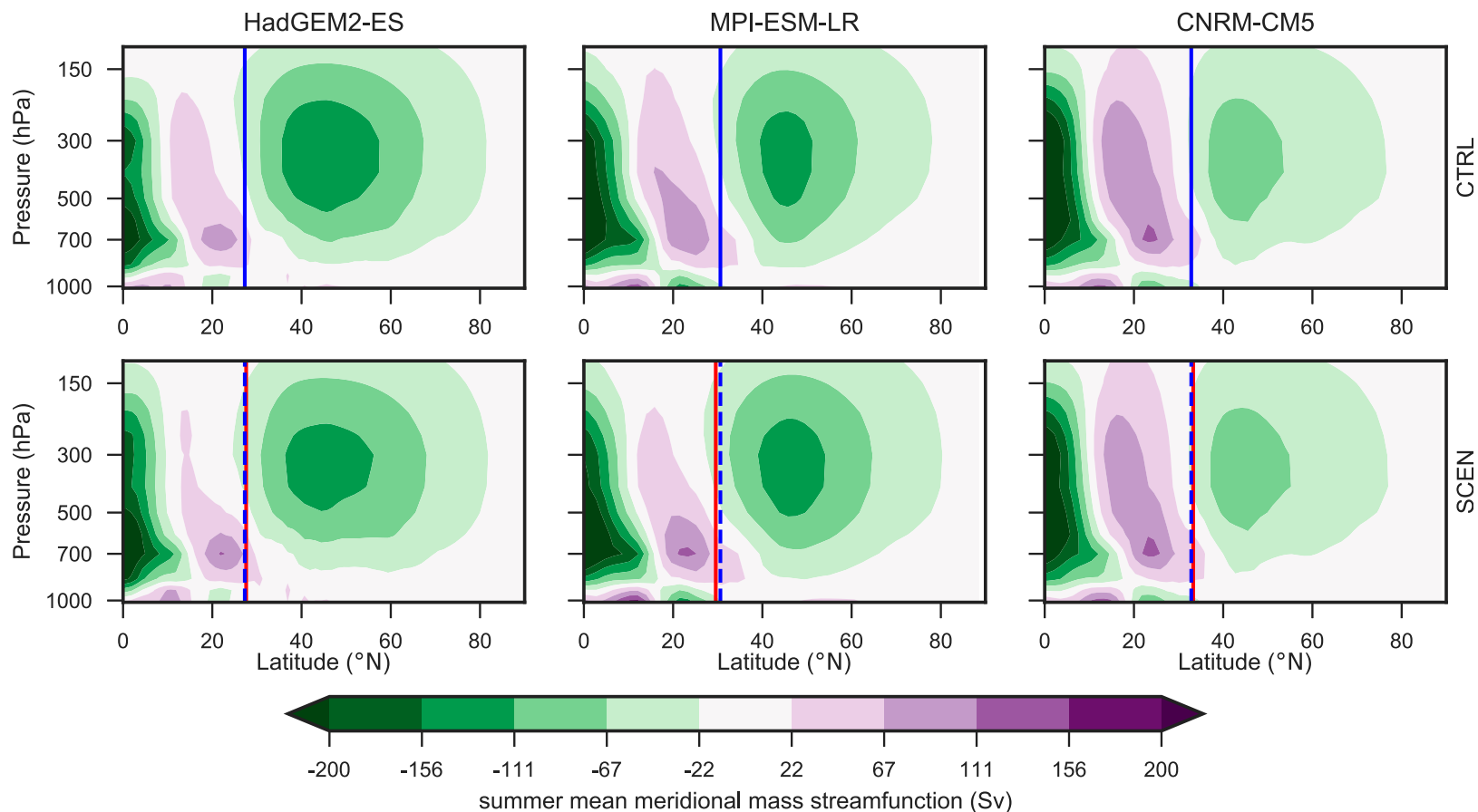

FIG. 5. Vertical cross sections of summer mean meridional mass streamfunction $\Psi_{\chi}$ (see section $2 \mathrm{~d}$ ) in the Northern Hemisphere averaged over the European longitudes $\left(10^{\circ} \mathrm{W}-35^{\circ} \mathrm{E}\right)$ in the (left) HadGEM2-ES, (middle) MPI-ESM-LR, and (right) CNRMCM5 global simulations. (top) The CTRL (1971-2000) period, and (bottom) the SCEN period (2070-99). Shading shows the magnitude of $\Psi_{\chi}$. The blue vertical line in the top row and the blue dashed line in the bottom row show the detected mean Hadley cell edge latitude during summer in the CTRL period. The red vertical line shows the mean Hadley cell edge latitude during summer in the SCEN period. Shifts in the mean summer Hadley cell edge latitude can be seen by comparing the blue dashed and the red solid lines.

Based on the data from the three simulations presented above, we thus find no conclusive connection between the changes in the summer-season Hadley circulation and the Mediterranean amplification.

Note that above we used GCM output for the analysis of the Hadley circulation and compared to RCM results. This approach is justified because the large-scale circulation in an RCM is governed by the GCM (Denis et al. 2002; Rummukainen 2010; Hall 2014). In addition, Fig. 6 allows us to compare the mean summer changes in meridional wind in the CCLM simulations and the global-driving simulations using vertical cross sections. Generally, we observe weak changes in meridional wind in both the RCM and GCM simulations. We find only small differences between the RCM and GCM simulations, especially in the southern part of the domain. Regarding systematic differences, we observe that changes in $v$ seem to be slightly weaker in the RCM simulations in the northern part of the domain.

Overall, the findings presented in this section are inconsistent with the notion of the Hadley cell expansion being the primary cause of the Mediterranean amplification. It follows that the Mediterranean warming amplification should be explicable by other processes included in the meridional change.

\section{2) MERIDIONAL LAPSE-RATE CHANGE GRADIENTS}

In the following, we are focusing on how the lapse rate is changing in the meridional direction and whether these changes can be related to the Mediterranean amplification. In the regional CCLM simulations, we compare the mean summer lapse-rate changes over land grid points in the Mediterranean (between $30^{\circ}$ and $44^{\circ} \mathrm{N}$ in the CCLM domain) and northern Europe (between $55^{\circ}$ and $70^{\circ} \mathrm{N}$ in the CCLM domain). Figure 7 shows mean vertical potential temperature change profiles based on the total change (SCEN - CTRL). At an altitude of around $8 \mathrm{~km}$, the simulations show the maximal warming. At the same altitude, the simulations show only a small spatial difference between the warming over the Mediterranean and northern Europe (Fig. 7 and additionally Fig. S4 for a map). The relative magnitude of the north-south summer warming difference in the upper troposphere is determined by the global-driving simulation. In the HadGEM2-ES-driven 

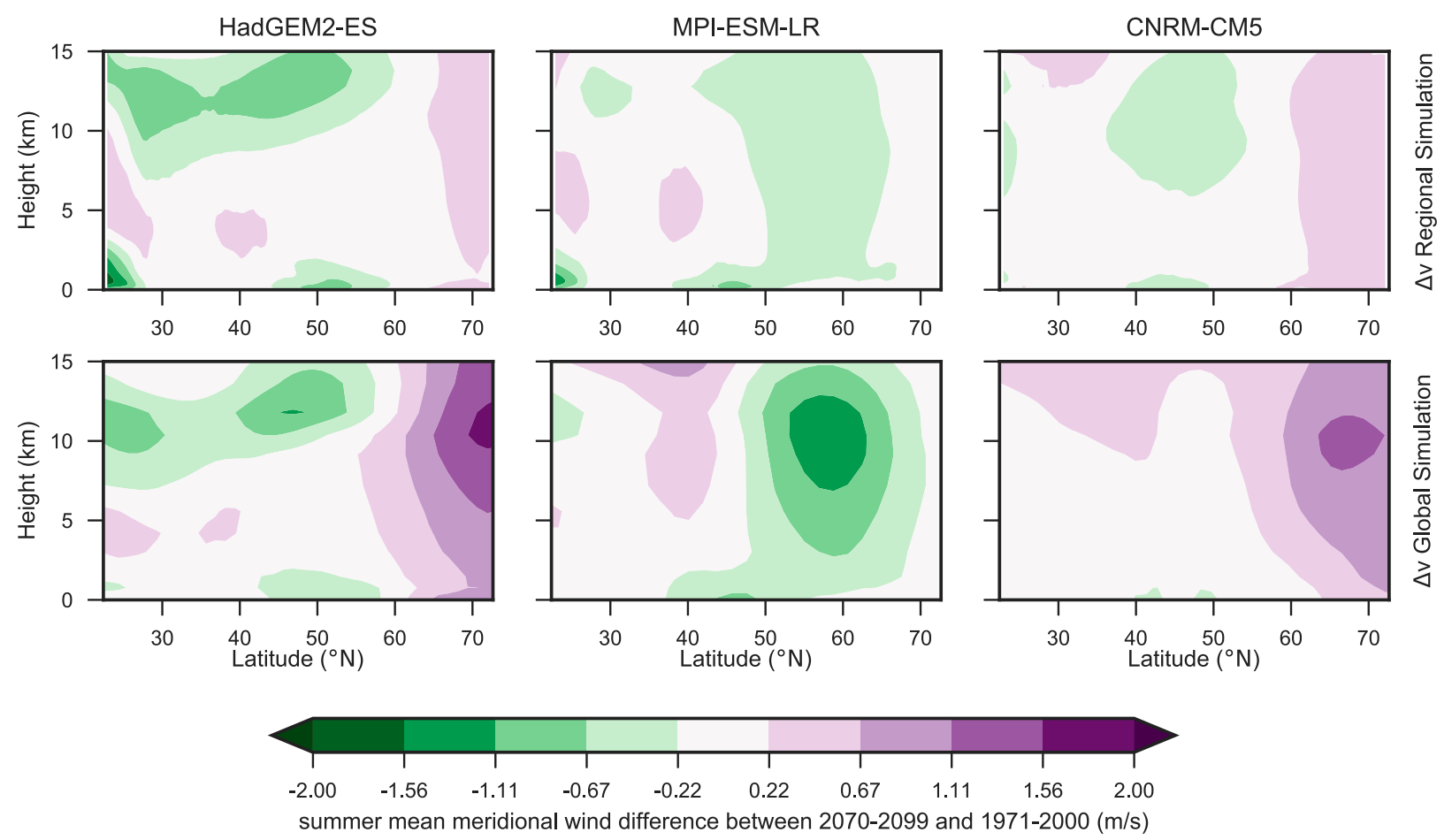

FIG. 6. Vertical cross sections of mean summer changes in the meridional wind component $v$ averaged over the European longitudes $\left(10^{\circ} \mathrm{W}-35^{\circ} \mathrm{E}\right)$ in (top) the regional climate simulations and (bottom) the corresponding global climate simulations: (left) the HadGEM2ES-driven CCLM simulation and the corresponding global simulation, (middle) MPI-ESM-LR, and (right) CNRM-CM5. Shading shows the difference in $v$ between the SCEN (2070-99) and CTRL (1971-2000) period.

simulation, the upper-tropospheric warming over the Mediterranean is weaker compared to northern Europe, while the opposite is true for the MPI-ESM-LR-driven simulation. In the CNRM-CM5-driven simulation, the upper-tropospheric warming is nearly identical over the Mediterranean and northern Europe.

However, in the lower troposphere, the potential temperature $(\theta)$ change is larger over the Mediterranean than over northern Europe in all three simulations (Fig. 7). This is consistent with the different vertical gradients in the potential temperature change between the Mediterranean and northern Europe. Over the Mediterranean, the vertical $\theta$ gradient or lapse-rate change is weak compared to northern Europe below an altitude of $10 \mathrm{~km}$. Typically, the lapse-rate change between CTRL and SCEN over the Mediterranean is around $0.15 \mathrm{~K} \mathrm{~km}^{-1}$, while it is about twice as strong in northern Europe with $0.3 \mathrm{~K} \mathrm{~km}^{-1}$. This implies that the magnitude of the near-surface warming over Mediterranean land grid points is reduced by less with respect to the maximum warming in the upper troposphere compared to the stronger reduction in northern Europe (Fig. 7). The different lapse-rate changes, combined with the small differences in upper-tropospheric warming, result in an amplified warming at the ground over the Mediterranean in all three simulations. The vertical lapse-rate change profiles over the Mediterranean shown in Fig. 7 are realistically represented in the simulations including the meridional change, but not in the simulations including only the thermodynamic or mean lapse-rate change (Fig. S11). The results shown in Fig. 7 therefore suggest that the north-south gradient between different lapse-rate changes is crucial to explain the Mediterranean amplification.

How can the geographical differences in the magnitude of lapse-rate changes be explained? Our hypothesis follows the reasoning of Joshi et al. (2008). They explain the land-sea contrast of global warming by gradients in near-surface relative humidity $(\mathrm{RH})$ that influence lapse-rate changes. We propose that gradients in relative humidity can explain the lapse-rate change contrast between the Mediterranean and northern Europe over land during the summer season. The suggested process is illustrated in Fig. 8 and the near-surface relative humidity gradients are shown in Fig. 9. As schematically illustrated in Fig. 8, vertical motions, triggered by, for example, convection or synoptic-scale eddies, lead to vertical mixing of air masses in the troposphere. If ascending air masses become saturated $(\mathrm{RH} \approx 100 \%)$ more latent heat is released in the upper troposphere in a warmer climate 

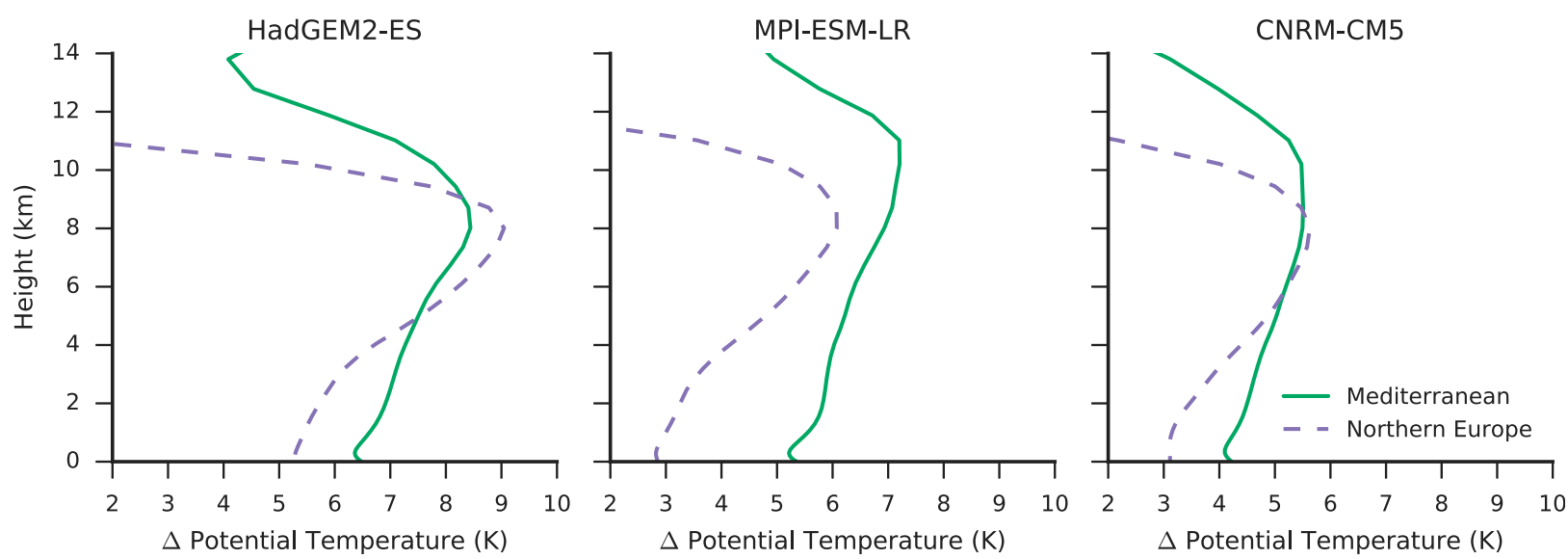

FIG. 7. Vertical profiles of mean summer potential temperature difference between SCEN (2070-99) and CTRL (1971-2000) in the regional CCLM simulations driven by (left) HadGEM2-ES, (middle) MPI-ESM-LR, and (right) CNRM-CM5. Profiles over MED land grid points (between $30^{\circ}$ and $44^{\circ} \mathrm{N}$ ) are shown by green lines, and profiles over northern European land grid points (between $55^{\circ}$ and $70^{\circ} \mathrm{N}$ ) are shown by purple dashed lines.

compared to a colder climate. The increased latent heat export from lower to higher altitudes manifests itself by a lapse-rate change seen as a smaller lower-tropospheric warming compared to the upper-tropospheric warming (Figs. 7, 8). If vertical motions do not come close to saturation, this process is inhibited.

The average summer near-surface RH in the Mediterranean is around $40 \%$ in both the CTRL and SCEN period (Fig. 9). However, in the northern areas of Europe, $\mathrm{RH}$ is found to be around $80 \%$ during CTRL and
SCEN (Fig. 9). Still, in the SCEN period, the northsouth gradient in low-level moisture availability is projected to slightly increase (Fig. 9).

Vertical motions may lead to saturation of air masses more easily in the moist environment as the air is closer to saturation on average. As saturation occurs more frequently, the influence of vertical motions on lapserate changes is stronger in northern Europe than in the Mediterranean (Fig. 8). In other words, in the Mediterranean, vertical motions are often influenced by dry
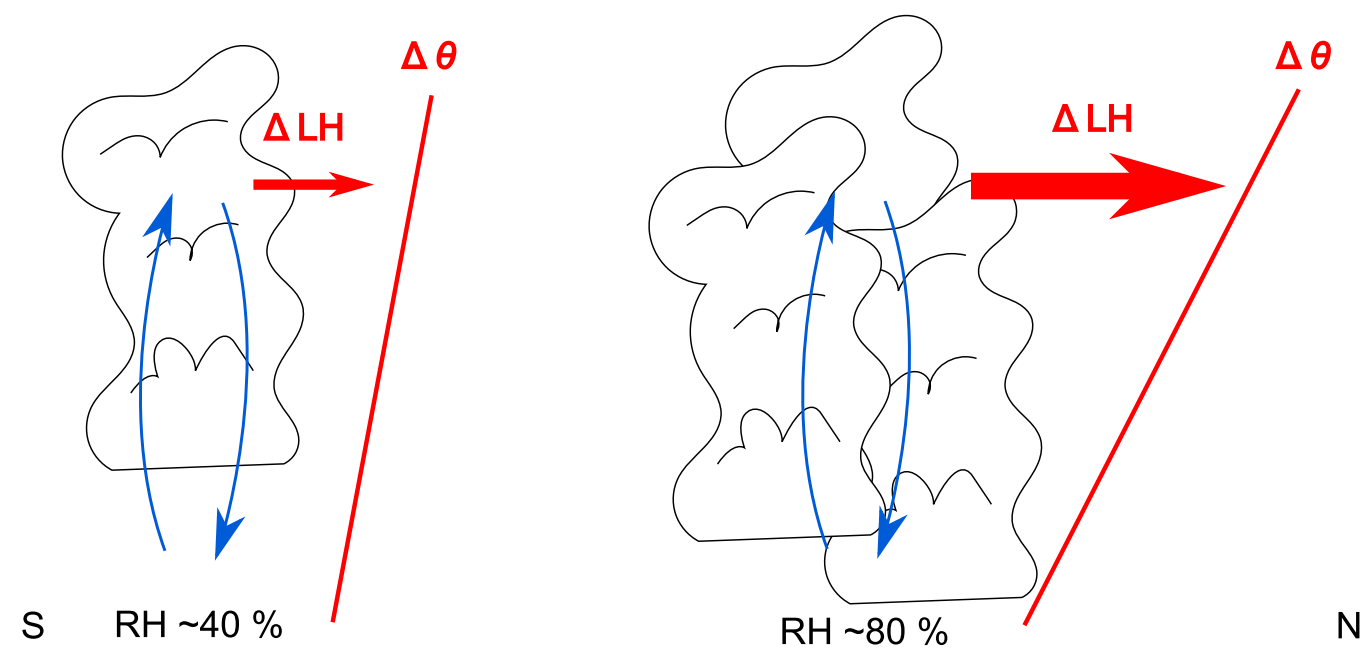

FIG. 8. Illustration of different summer lapse-rate changes over land areas in the MED and northern Europe. The vertical cross section is from (left) the MED in the south (S) to (right) northern Europe (N). The near-surface RH is around $40 \%$ in the MED and around $80 \%$ in northern Europe. Vertical up- and downward motions are shown by blue arrows. Because of the higher moisture content, vertical motions are more often saturated in northern Europe, yielding more clouds. In a warmer climate, saturated vertical motions release more latent heat into the troposphere ( $\Delta \mathrm{LH}$; red arrows). More latent heat is released in moister northern Europe compared to the drier MED (red arrow size). A vertical profile for the potential temperature $(\theta)$ change in response to $\Delta \mathrm{LH}$ is shown by the red line, where larger changes are to the right. 

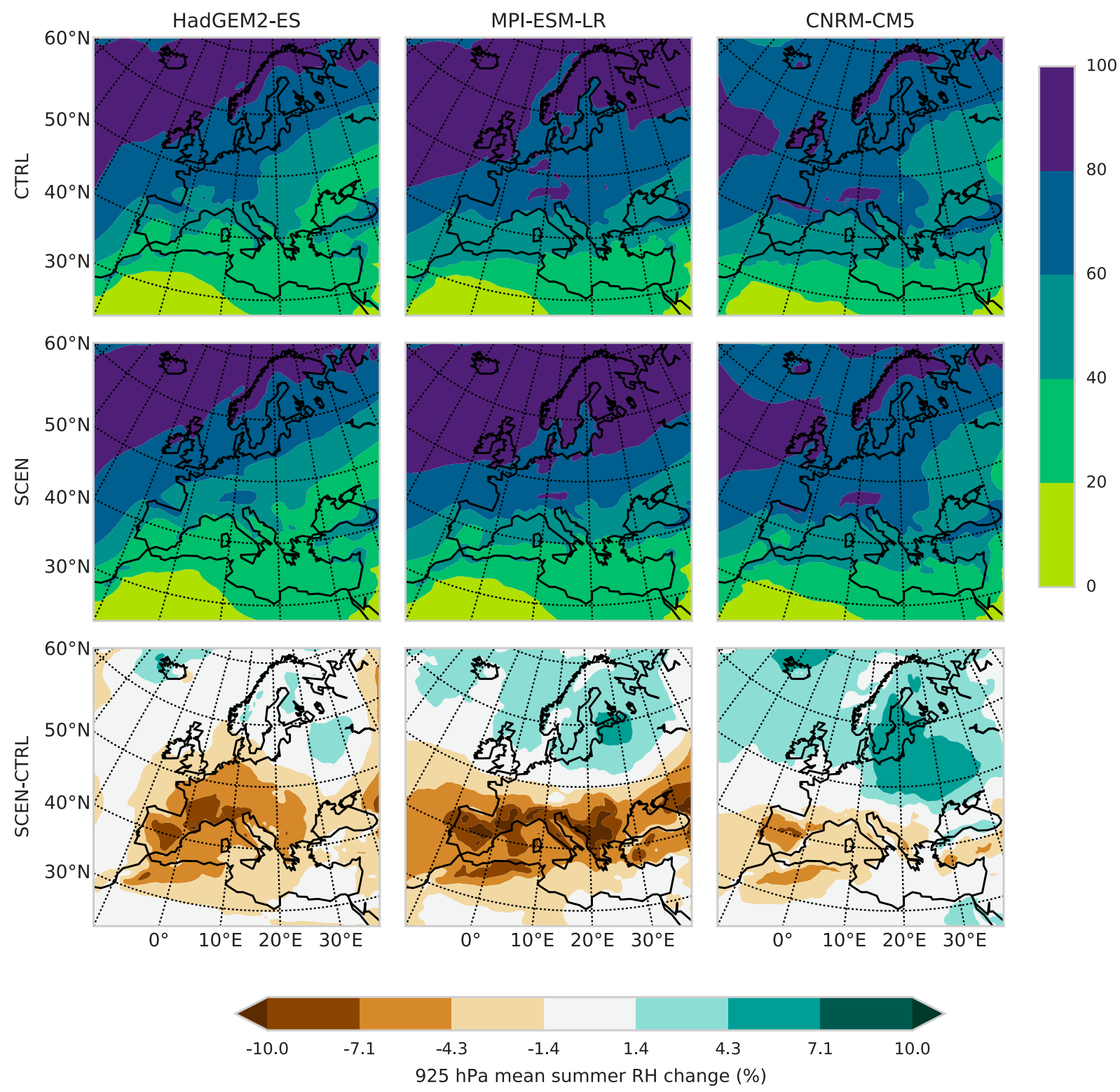

FIG. 9. Maps of the distribution and changes in mean summer RH on $925 \mathrm{hPa}$ in the CCLM simulations driven by (left) HadGEM2ES, (middle) MPI-ESM-LR, and (right) CNRM-CM5. (top) Shading shows the summer mean RH values during the CTRL period (1971-2000) (see the color bar on the right). (middle) Shading shows the summer mean RH values during the SCEN period (2070-99) (also using the color bar on the right). (bottom) Change expressed as SCEN-CTRL (see the bottom color bar). Note that the range of $\mathrm{RH}$ changes shown by the bottom bar is 5 times smaller compared to the range of absolute RH shown by the right bar.

adiabatic processes, which are independent of temperature and do not lead to lapse-rate changes. In comparison, in northern Europe, vertical motions are more dependent on temperature changes because of moist adiabatic processes, which do lead to lapse-rate changes, manifested by an increase of the dry static stability, when the temperatures rise. Thus, the vertical mixing of air with different $\mathrm{RH}$ values should lead to different potential temperature change profiles when the climate warms. Given that the upper-tropospheric warming is horizontally nearly uniform, the different potential temperature change profiles can control near-surface temperature increases (see Joshi et al. 2008). We therefore hypothesize that the north-south humidity gradient in the lower troposphere can explain the north-south lapse-rate change gradients during summer over Europe (Fig. 7).

The influence of near-surface relative humidity gradients and changes (Fig. 9) on lapse rates has mostly been investigated and described for tropical areas (Joshi 

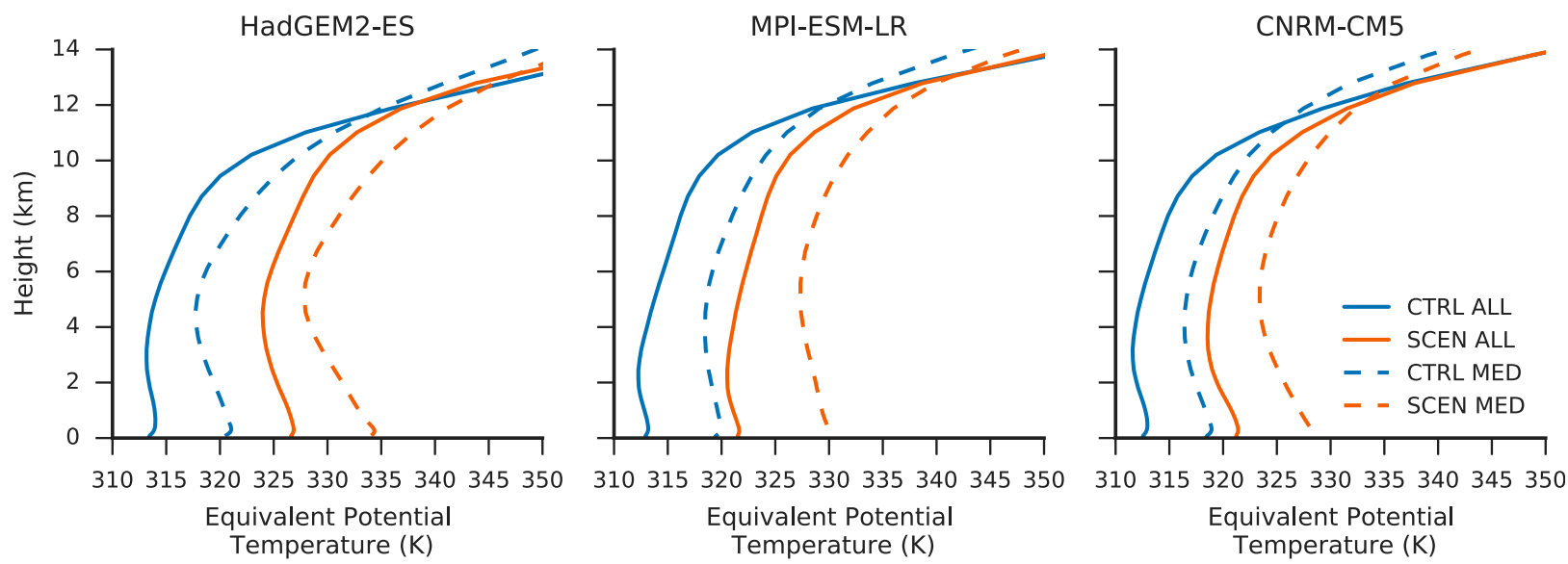

FIG. 10. Vertical profiles of mean summer equivalent potential temperature $\theta_{e}$ over land grid points in the CCLM simulations driven by (left) HadGEM2-ES, (middle) MPI-ESM-LR, and (right) CNRM-CM5. The blue lines show profiles from the CTRL period (1971-2000) and the red lines show profiles from the SCEN period (2070-99). The solid lines show the horizontal mean of all land grid points in the domain (ALL) and the dashed lines show the mean over MED land grid points (between $30^{\circ}$ and $44^{\circ} \mathrm{N}$ ).

et al. 2008; Byrne and O'Gorman 2013a,b, 2018). This is because the influence of relative humidity on lapse-rate changes ultimately depends on the behavior of the moist adiabatic lapse rate in a warming climate. It is well known that the tropical tropospheric stratification is well described by a moist adiabat due to strong vertical mixing [i.e., the equivalent potential temperature $\theta_{e}$ is approximately constant with height within the troposphere]. Given that we hypothesize that the same processes are relevant in the European summer season, we also expect that the stratification in summer approximately follows the moist adiabat. This can be seen by analyzing the equivalent potential temperature profiles shown in Fig. 10. Averaged over all land grid points in the CCLM domain, $\theta_{e}$ remains fairly constant with height throughout the troposphere in both the CTRL and SCEN periods. However, the average summer profiles over Mediterranean land grid points exhibit conditional instability in the lower troposphere, that is, the mean stratification is unstable with respect to moist adiabatic vertical motions. This kind of stratification can only be sustained if moist adiabatic vertical motions are often inhibited because of dryness, which agrees with our hypothesis discussed above and in Fig. 8.

As described, lapse-rate changes are mainly caused by thermodynamic processes that are thought to be well represented by current climate models. The connection between robust thermodynamic changes and the Mediterranean amplification also offers an explanation for the fact that the Mediterranean amplification is a common feature in climate projections (Giorgi and Lionello 2008). In our simulations, the Mediterranean warming amplification is robust across simulations despite quite large differences in the strength and position of the subtropical or polar jets (Fig. 11). This also suggests that processes that are less dependent on circulation changes, like changes in the tropospheric lapse rates, are more likely to cause the Mediterranean warming amplification in model projections.

Our analysis of the contributions to climate change suggests that the contribution of the meridional change explains the largest fraction of the Mediterranean warming amplification due to differential changes in the lapse rates in the meridional direction. The notion that the Mediterranean amplification is caused by a poleward expansion of the Hadley cell is not supported by our results, because the Hadley circulation is weak and exhibits no consistent poleward expansion in the summer season over Europe in the simulations we analyzed.

\section{Conclusions}

In this study, we investigated possible causes of the Mediterranean warming amplification as projected in response to greenhouse gas forcing during the summer season at the end of the century. We downscaled three different GCMs using the pseudo-global warming framework presented in Kröner et al. (2017) and KLS. Expanding on this previous study, we separated the total climate change signal into five contributions. We separated the contributions of thermodynamic change, mean lapse-rate change, meridional change, 3D change, and high-frequency circulation change in the three downscaled GCMs.

We found that the most important contribution to the Mediterranean amplification in our separation stems from the meridional change, which has been assessed for 

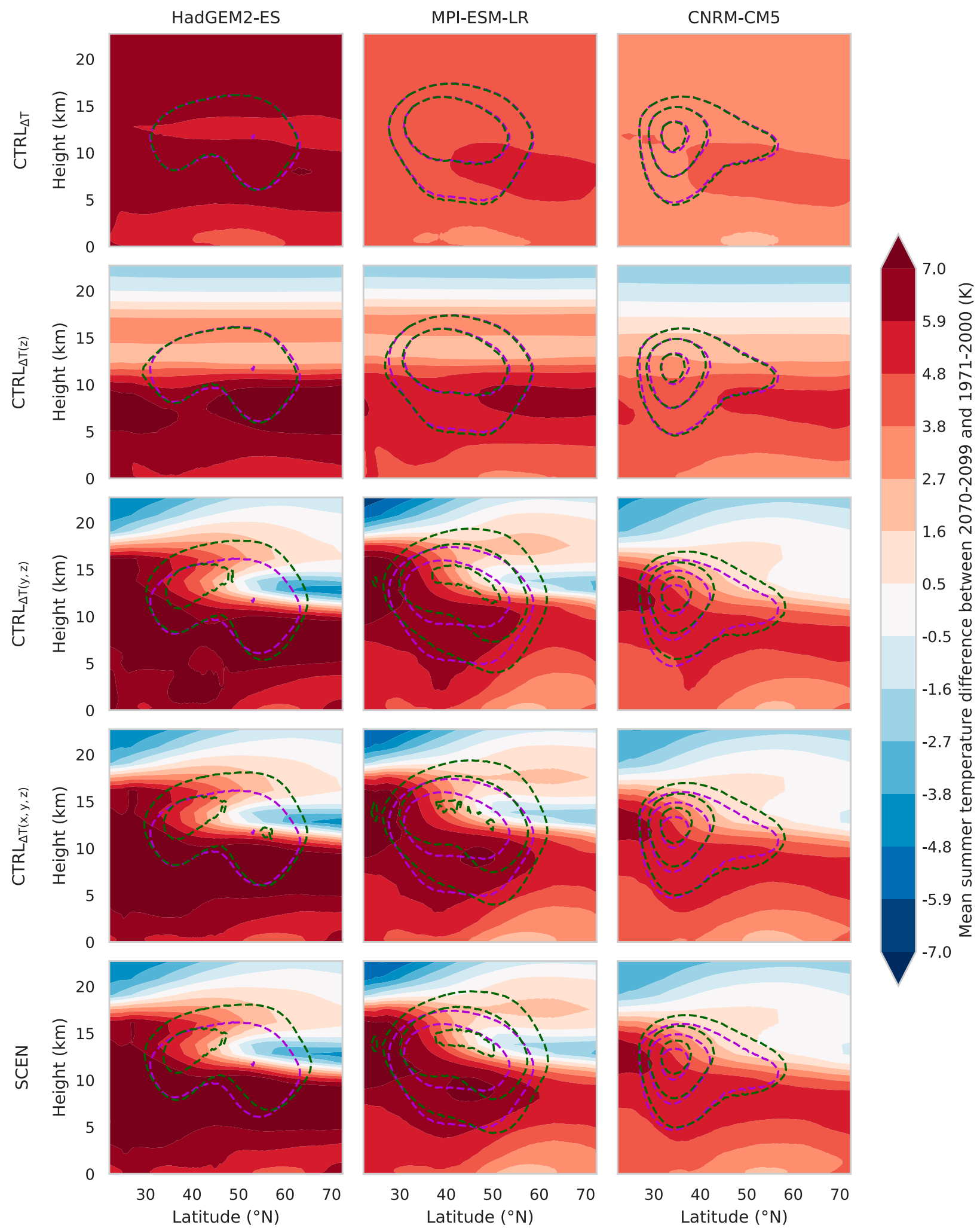

FIG. 11. Vertical cross sections of mean summer changes in temperature and wind in the CCLM simulations shown in each row with respect to the CTRL simulation. (top to bottom) $\mathrm{CTRL}_{\Delta T}, \mathrm{CTRL}_{\Delta T(z)}$, CTRL $\mathrm{CTT}_{\Delta, z)}, \mathrm{CTRL}_{\Delta T(x, y, z)}$, and SCEN (see also section $2 \mathrm{c}$ and appendix A). Columns show the global-driving simulations: (left) HadGEM2-ES, (middle) MPI-ESM-LR, and (right) CNRM-CM5. Temperature changes are shown by the shading. Dashed contours show mean zonal wind $u$ with contours at 10,15 , and $20 \mathrm{~m} \mathrm{~s}^{-1}$. Purple contours show the wind in the associated CTRL simulation, while green contours show the wind in the displayed simulation. Thus, changes in the mean zonal wind or the mean jet can be seen comparing the purple and the green contours. 
the first time in this study. The contribution of the meridional change represents seasonal circulation shifts such as a poleward expansion of the Hadley cell and meridional lapse-rate change gradients.

A detailed analysis showed no connection between a poleward expansion of the Hadley cell and the Mediterranean amplification. In the European summer season, the Hadley circulation is only very weak and even shows an equatorward contraction in some of the global models under consideration. Hence, we suggest that during summer, Hadley circulation changes only have a small influence on the European climate change projected at the end of the century. Previous studies have also not found a substantial influence of Hadley circulation changes on climate change in subtropical land areas (He and Soden 2017; Schmidt and Grise 2017) nor substantial Hadley circulation changes in summer (D'Agostino et al. 2017), consistent with our findings. The simulated Hadley circulation changes should, however, be interpreted with caution, since in historical climate simulations, discrepancies between simulated and observed Hadley cell expansions are found (Birner et al. 2014; Lucas et al. 2014; Heffernan 2016).

Our results confirm the findings of Kröner et al. (2017) and KLS, who found an influence of lapse-rate changes on the Mediterranean amplification. In addition, we find that the north-south gradient of lapse-rate changes between the Mediterranean and northern Europe is especially relevant. By the end of the current century, the strongest warming is simulated in the upper troposphere, and only small geographical differences between the upper-tropospheric warming exist over the European continent. The lapse-rate change in the Mediterranean is weak, which means that the near-surface warming is only a little smaller than the maximum upper-tropospheric warming. The lapse-rate change in northern Europe is substantially stronger compared to the Mediterranean, thus the near-surface warming is substantially smaller compared to the maximum warming in the upper troposphere. In line with the reasoning of Joshi et al. (2008) and Byrne and O'Gorman (2013a,b), we suggest that differing lapserate changes may arise because of gradients in the lowlevel moisture availability. The Mediterranean land areas are comparably dry, therefore vertical mixing is often influenced by dry adiabatic processes, leading to rather uniform increases of potential temperatures throughout the troposphere. In the more humid areas in northern Europe, moist adiabatic processes lead to increased latent heat export to higher altitudes as the climate warms, yielding larger vertical gradients in the potential temperature changes. We suggest that the north-south contrast in lapse-rate changes is the most important factor causing the Mediterranean warming amplification.

The ensemble of simulations considered used three different driving GCMs, and this has proven helpful to assess the robustness of the analyzed processes. However, a caveat of our approach is that we only used one RCM. It would be intriguing to investigate whether our results can be confirmed using another RCM. Furthermore, lapse-rate changes partially depend on convective processes, which are parameterized in our simulations. Therefore, the simulated lapse-rate changes could be improved by convection-resolving climate simulations (Leutwyler et al. 2017).

We did not further address the connection between the Mediterranean warming amplification and the Mediterranean drying in summer in this study, which might be a topic for future research. Previous findings show a direct connection of the summer drying to the increased warming in the Mediterranean (Rowell and Jones 2006; KLS). This connection is also plausible based on our separation of contributions to climate change, since the meridional change dominates both the enhanced warming and drying over the Mediterranean (Fig. 3). We did not address seasonal differences in the climate change signals in detail, yet the supplemental material contains additional figures that allow a comparison between the simulation results for summer and winter.

Acknowledgments. We thank Michael Byrne and two anonymous reviewers for their helpful and constructive feedback on earlier versions of this manuscript. We acknowledge PRACE for awarding us computing resources on Piz Daint at the Swiss National Supercomputing Center (CSCS) in Lugano. Furthermore, we want to acknowledge the COSMO and CLM communities for developing and maintaining the RCM. We also acknowledge the World Climate Research Programme's Working Group on Coupled Modeling, responsible for CMIP, and we thank the climate modeling groups for producing and making available their model output. We thank Urs Beyerle for preparing the CMIP5 data for our analysis.

\section{APPENDIX A}

\section{Simulation Details}

This section contains the technical details of our PGW simulations. Each contribution to climate change shown in Fig. 1 is described in a separate subsection corresponding to one of the subsections in $2 \mathrm{c}$. 


\section{a. Thermodynamic change}

TD is obtained by adding a vertically and horizontally uniform temperature change (i.e., $\Delta T=$ SCEN - CTRL) to the CTRL simulation and subtracting it form the SCEN simulation (Fig. 1). The domain mean $\Delta T$ at $850 \mathrm{hPa}$ is used. For these simulations, the day-to-day weather patterns of the driving global simulation remain mostly unchanged (Figs. 1, 11). TD is calculated as the average difference between the parent simulations and the modified simulations, that is,

$$
\mathrm{TD}:=\frac{\left[\mathrm{CTRL}_{\Delta T}-\mathrm{CTRL}\right]+\left[\mathrm{SCEN}-\mathrm{SCEN}_{\Delta T}\right]}{2} .
$$

Since we modify the temperature in our simulations, we also have to adapt the pressure $p$ according to the hydrostatic balance to maintain physical consistency. The specific humidity $q$ at the model boundaries is altered according to the ClausiusClapeyron relation assuming unchanged relative humidity (RH).

All the modifications of the model boundary fields include a representation of the annual cycle of the respective variable $(T, p$, or $q)$. The annual cycle is a smoothed 30-yr average, computed using a spectral filter (Kröner et al. 2017). The sea surface temperature (SST) is changed identically to the lowest atmospheric level in all PGW simulations.

\section{b. Mean lapse-rate change}

LR is simulated analogously to TD, except that the domain-mean temperature change on every vertical model level is taken into account separately. As for TD, weather systems are only marginally altered (Figs. 1,11). LR is then calculated as follows:

$\mathrm{LR}:=\frac{\left[\mathrm{CTRL}_{\Delta T(z)}-\mathrm{CTRL}_{\Delta T}\right]+\left[\mathrm{SCEN}_{\Delta T}-\mathrm{SCEN}_{\Delta T(z)}\right]}{2}$.

\section{c. Meridional change}

For MC, variations in the temperature change in meridional direction are taken into account, in addition to vertical variations $\Delta T(y, z)$, where $y$ denotes the meridional direction. Since we change the meridional temperature gradient, we also adapt the horizontal wind components $u$ and $v$ to be consistent with the thermal wind balance. The simulations including the meridional change $\mathrm{CTRL}_{\Delta T(y, z)}$ and $\operatorname{SCEN}_{\Delta T(y, z)}$ are used in an analogous way to calculate MC:

$\mathrm{MC}:=$

$\frac{\left[\mathrm{CTRL}_{\Delta T(y, z)}-\mathrm{CTRL}_{\Delta T(z)}\right]+\left[\mathrm{SCEN}_{\Delta T(z)}-\mathrm{SCEN}_{\Delta T(y, z)}\right]}{2}$.

In contrast to $\mathrm{TD}$ and $\mathrm{LR}$, the simulations $\mathrm{CTRL}_{\Delta T(y, z)}$ and $\operatorname{SCEN}_{\Delta T(y, z)}$ do not assume unchanged $\mathrm{RH}$, as latitudinal and vertical changes of RH between SCEN and CTRL are also taken into account. The changes in $\mathrm{RH}$ are then converted to specific humidity $q$, which are needed as boundary field for CCLM. This intermediate step has been found to prevent artificial drying near the model boundaries (KLS).

In summary, for MC, we modify the lateral boundaries using $\Delta T(y, z), \Delta p(y, z), \Delta u(y, z), \Delta v(y, z)$, and $\Delta q(y, z)$. In practical terms, we first compute a smoothed annual cycle of the mentioned variables in the same manner as for TD and LR. However, the annual cycle is computed at every grid point instead of taking the horizontal mean. Then the zonal averages of the variables are computed and the annual cycle of the zonal averages is finally used to modify the boundary fields at the respective latitude and height.

\section{d. $3 D$ change}

For 3D, the CTRL and SCEN simulations are modified using $\Delta T(x, y, z)$, yielding the $\mathrm{CTRL}_{\Delta T(x, y, z)}$ and $\mathrm{SCEN}_{\Delta T(x, y, z)}$ simulations. CTRL $\mathrm{CT}_{\Delta(x, y, z)}$ and $\operatorname{SCEN}_{\Delta T(x, y, z)}$ are simulated in the same manner as $\operatorname{CTRL}_{\Delta T(y, z)}$ and $\operatorname{SCEN}_{\Delta T(y, z)}$ described in the previous subsection, but no zonal averaging is carried out. These simulations are still provided with the day-to-day weather patterns of the parent simulations at the lateral boundaries, as also shown in Fig. 1. The 3D change is then calculated by

$3 \mathrm{D}:=\frac{\left[\mathrm{CTRL}_{\Delta T(x, y, z)}-\mathrm{CTRL}_{\Delta T(y, z)}\right]+\left[\mathrm{SCEN}_{\Delta T(y, z)}-\operatorname{SCEN}_{\Delta T(x, y, z)}\right]}{2}$.

\section{e. High-frequency circulation change}

The last contribution we are separating from the total climate change is HF (residual), given as,

$\mathrm{HF}:=\frac{\left[\mathrm{SCEN}-\mathrm{CTRL}_{\Delta T(x, y, z)}\right]+\left[\mathrm{SCEN}_{\Delta T(x, y, z)}-\mathrm{CTRL}\right]}{2}$. 


\section{f. Total change}

By design of our experiments, the sum of Eqs. (A1)(A5) yields,

$\mathrm{TOT}=\mathrm{TD}+\mathrm{LR}+\mathrm{MC}+3 \mathrm{D}+\mathrm{HF}=\mathrm{SCEN}-\mathrm{CTRL}$.

Thus, our methodology yields an additive separation; that is, there are no interaction terms in the analysis (Schär and Kröner 2017).

\section{APPENDIX B}

\section{List of Symbols}

a Earth radius

$g$ Gravitational acceleration

LH Latent heat of evaporation

$p \quad$ Pressure

$q \quad$ Specific humidity

RH Relative humidity

$T$ Temperature

$\theta \quad$ Potential temperature

$\theta_{e} \quad$ Equivalent potential temperature

$u \quad$ Zonal wind component

$v \quad$ Meridional wind component

$v_{\chi} \quad$ Irrotational component of the meridional wind

$x \quad$ Zonal direction

$y \quad$ Meridional direction

$z \quad$ Height

$\Delta \quad$ Change of a quantity

$\lambda \quad$ Longitude

$\phi \quad$ Latitude

$\Psi \quad$ Meridional mass streamfunction

$\Psi_{\chi} \quad$ Meridional mass streamfunction based on the Helmholtz-decomposed wind

\section{REFERENCES}

Allen, M. R., and W. J. Ingram, 2002: Constraints on future changes in climate and the hydrologic cycle. Nature, 419, 224-232, https://doi.org/10.1038/nature01092; Corrigendum, 489, 590, https://doi.org/10.1038/nature11456.

Anderegg, W. R. L., J. M. Kane, and L. D. L. Anderegg, 2013: Consequences of widespread tree mortality triggered by drought and temperature stress. Nat. Climate Change, 3, 30-36, https://doi.org/10.1038/nclimate1635.

Birner, T., S. M. Davis, and D. Seidel, 2014: The changing width of Earth's tropical belt. Phys. Today, 67, 38, https://doi.org/ 10.1063/PT.3.2620.

Bladé, I., B. Liebmann, D. Fortuny, and G. J. van Oldenborgh, 2012: Observed and simulated impacts of the summer NAO in Europe: Implications for projected drying in the Mediterranean region. Climate Dyn., 39, 709-727, https://doi.org/10.1007/ s00382-011-1195-x.
Bony, S., and Coauthors, 2006: How well do we understand and evaluate climate change feedback processes? J. Climate, 19, 3445-3482, https://doi.org/10.1175/JCLI3819.1.

Byrne, M. P., and P. A. O'Gorman, 2013a: Land-ocean warming contrast over a wide range of climates: Convective quasiequilibrium theory and idealized simulations. J. Climate, 26, 4000-4016, https://doi.org/10.1175/JCLI-D-12-00262.1.

, and _ 2013b: Link between land-ocean warming contrast and surface relative humidities in simulations with coupled climate models. Geophys. Res. Lett., 40, 5223-5227, https:// doi.org/10.1002/grl.50971.

— midity directly linked to ocean warming. Proc. Natl. Acad. Sci. USA, 115, 4863-4868, https://doi.org/10.1073/pnas.1722312115.

D'Agostino, R., and P. Lionello, 2017: Evidence of global warming impact on the evolution of the Hadley circulation in ECMWF centennial reanalyses. Climate Dyn., 48, 3047-3060, https:// doi.org/10.1007/s00382-016-3250-0.

— — _ O. Adam, and T. Schneider, 2017: Factors controlling Hadley circulation changes from the Last Glacial Maximum to the end of the 21st century. Geophys. Res. Lett., 44, 8585-8591, https://doi.org/10.1002/2017GL074533.

Dawson, A., 2016: Windspharm: A high-level library for global wind field computations using spherical harmonics. J. Open Res. Software, 4, e31, https://doi.org/10.5334/jors.129.

Denis, B., R. Laprise, D. Caya, and J. Côté, 2002: Downscaling ability of one-way nested regional climate models: The BigBrother Experiment. Climate Dyn., 18, 627-646, https:// doi.org/10.1007/s00382-001-0201-0.

Doms, G., U. Schättler, and M. Baldauf, 2011: A Description of the Nonhydrostatic Regional COSMO Model: Part VII: User's Guide. Deutscher Wetterdienst, 221 pp.

Fischer, E. M., and C. Schär, 2010: Consistent geographical patterns of changes in high-impact European heatwaves. Nat. Geosci., 3, 398-403, https://doi.org/10.1038/ngeo866.

Giorgi, F., 2006: Climate change hot-spots. Geophys. Res. Lett., 33, L08707, https://doi.org/10.1029/2006GL025734.

, and P. Lionello, 2008: Climate change projections for the Mediterranean region. Global Planet. Change, 63, 90-104, https://doi.org/10.1016/j.gloplacha.2007.09.005.

Gudmundsson, L., S. I. Seneviratne, and X. Zhang, 2017: Anthropogenic climate change detected in European renewable freshwater resources. Nat. Climate Change, 7, 813-816, https:// doi.org/10.1038/nclimate3416.

Hall, A., 2014: Projecting regional change. Science, 346, 1460-1462, https://doi.org/10.1126/science.aaa0629.

Hawkins, E., and R. Sutton, 2009: The potential to narrow uncertainty in regional climate predictions. Bull. Amer. Meteor. Soc., 90, 1095-1108, https://doi.org/10.1175/2009BAMS2607.1.

He, J., and B. J. Soden, 2017: A re-examination of the projected subtropical precipitation decline. Nat. Climate Change, $\mathbf{7}$, 53-57, https://doi.org/10.1038/nclimate3157; Corrigendum, 8, 921, https://doi.org/10.1038/s41558-018-0265-z.

Heffernan, O., 2016: The mystery of the expanding tropics. Nature, 530, 20-22, https://doi.org/10.1038/530020a.

Held, I. M., and B. J. Soden, 2006: Robust responses of the hydrological cycle to global warming. J. Climate, 19, 5686-5699, https://doi.org/10.1175/JCLI3990.1; Corrigendum, 24, 1559_ 1560, https://doi.org/10.1175/2010JCLI4045.1.

Hoerling, M., J. Eischeid, J. Perlwitz, X. Quan, T. Zhang, and P. Pegion, 2012: On the increased frequency of Mediterranean drought. J. Climate, 25, 2146-2161, https://doi.org/10.1175/ JCLI-D-11-00296.1. 
Hu, Y., and Q. Fu, 2007: Observed poleward expansion of the Hadley circulation since 1979. Atmos. Chem. Phys., 7, 52295236, https://doi.org/10.5194/acp-7-5229-2007.

Jacob, D., and Coauthors, 2014: EURO-CORDEX: New highresolution climate change projections for European impact research. Reg. Environ. Change, 14, 563-578, https://doi.org/ 10.1007/s10113-013-0499-2.

Joshi, M. M., J. M. Gregory, M. J. Webb, D. M. H. Sexton, and T. C. Johns, 2008: Mechanisms for the land/sea warming contrast exhibited by simulations of climate change. Climate Dyn., $\mathbf{3 0}$, 455-465, https://doi.org/10.1007/s00382-007-0306-1.

Kawase, H., T. Yoshikane, M. Hara, F. Kimura, T. Yasunari, B. Ailikun, H. Ueda, and T. Inoue, 2009: Intermodel variability of future changes in the Baiu rainband estimated by the pseudo global warming downscaling method. J. Geophys. Res., 114, D24110, https://doi.org/10.1029/2009JD011803.

Kotlarski, S., and Coauthors, 2014: Regional climate modeling on European scales: A joint standard evaluation of the EURO-CORDEX RCM ensemble. Geosci. Model Dev., 7, 1297-1333, https://doi.org/10.5194/gmd-7-1297-2014.

Kröner, N., S. Kotlarski, E. Fischer, D. Lüthi, E. Zubler, and C. Schär, 2017: Separating climate change signals into thermodynamic, lapse-rate and circulation effects: Theory and application to the European summer climate. Climate Dyn., 48, 3425-3440, https://doi.org/10.1007/s00382-016-3276-3.

Lackmann, G. M., 2013: The south-central U.S. flood of May 2010: Present and future. J. Climate, 26, 4688-4709, https://doi.org/ 10.1175/JCLI-D-12-00392.1.

Leutwyler, D., D. Lüthi, N. Ban, O. Fuhrer, and C. Schär, 2017: Evaluation of the convection-resolving climate modeling approach on continental scales. J. Geophys. Res. Atmos., 122 5237-5258, https://doi.org/10.1002/2016JD026013.

Lorenzo, M. N., A. M. Ramos, and S. Brands, 2016: Present and future climate conditions for winegrowing in Spain. Reg. Environ. Change, 16, 617-627, https://doi.org/10.1007/s10113-015-0883-1.

Lu, J., G. Vecchi, and T. Reichler, 2007: Expansion of the Hadley cell under global warming. Geophys. Res. Lett., 34, L06805, https://doi.org/10.1029/2006GL028443; Corrigendum, 34, L14808, https://doi.org/10.1029/2007GL030931.

Lucas, C., B. Timbal, and H. Nguyen, 2014: The expanding tropics: A critical assessment of the observational and modeling studies. Wiley Interdiscip. Rev.: Climate Change, 5, 89-112, https://doi.org/10.1002/wcc.251.

Mahoney, K., D. Swales, M. J. Mueller, M. Alexander, M. Hughes, and K. Malloy, 2018: An examination of an inland-penetrating atmospheric river flood event under potential future thermodynamic conditions. J. Climate, 31, 6281-6297, https://doi.org/ 10.1175/JCLI-D-18-0118.1.

Martin, G. M., and Coauthors, 2011: The HadGEM2 family of Met Office Unified Model climate configurations. Geosci. Model Dev., 4, 723-757, https://doi.org/10.5194/gmd-4-723-2011.

Moss, R. H., and Coauthors, 2010: The next generation of scenarios for climate change research and assessment. Nature, 463, 747756, https://doi.org/10.1038/nature08823.

Nguyen, H., H. H. Hendon, E.-P. Lim, G. Boschat, E. Maloney, and B. Timbal, 2018: Variability of the extent of the Hadley circulation in the Southern Hemisphere: A regional perspective. Climate Dyn., 50, 129-142, https://doi.org/10.1007/ s00382-017-3592-2.

Nishizawa, S., S. A. Adachi, Y. Kajikawa, T. Yamaura, K. Ando, R. Yoshida, H. Yashiro, and H. Tomita, 2018: Decomposition of the large-scale atmospheric state driving downscaling: A perspective on dynamical downscaling for regional climate study. Prog. Earth Planet. Sci., 5, https://doi.org/10.1186/ s40645-017-0159-0.

Oort, A. H., and J. J. Yienger, 1996: Observed interannual variability in the Hadley Circulation and its connection to ENSO. J. Climate, 9, 2751-2767, https://doi.org/10.1175/1520-0442 (1996) $009<2751$ :OIVITH $>2.0$. CO;2.

Prein, A. F., R. M. Rasmussen, K. Ikeda, C. Liu, M. P. Clark, and G. J. Holland, 2017a: The future intensification of hourly precipitation extremes. Nat. Climate Change, 7, 48-52, https:// doi.org/10.1038/nclimate3168.

— C. Liu, K. Ikeda, S. B. Trier, R. M. Rasmussen, G. J. Holland, and M. P. Clark, 2017b: Increased rainfall volume from future convective storms in the US. Nat. Climate Change, 7, 880-884, https://doi.org/10.1038/s41558-017-0007-7.

Rasmussen, R. M., and Coauthors, 2011: High-resolution coupled climate runoff simulations of seasonal snowfall over Colorado: A process study of current and warmer climate. J. Climate, 24, 3015-3048, https://doi.org/10.1175/2010JCLI3985.1.

— , and Coauthors, 2014: Climate change impacts on the water balance of the Colorado headwaters: High-resolution regional climate model simulations. J. Hydrometeor., 15, 1091-1116, https://doi.org/10.1175/JHM-D-13-0118.1.

Riahi, K., and Coauthors, 2011: RCP 8.5-A scenario of comparatively high greenhouse gas emissions. Climatic Change, 109, 33-57, https://doi.org/10.1007/s10584-011-0149-y.

Rockel, B., A. Will, and A. Hense, 2008: The regional climate model COSMO-CLM (CCLM). Meteor. Z., 17, 347-348, https://doi.org/10.1127/0941-2948/2008/0309.

Rowell, D. P., and R. G. Jones, 2006: Causes and uncertainty of future summer drying over Europe. Climate Dyn., 27, 281-299, https://doi.org/10.1007/s00382-006-0125-9.

Rummukainen, M., 2010: State-of-the-art with regional climate models. Wiley Interdiscip. Rev.: Climate Change, 1, 82-96, https://doi.org/10.1002/wcc.8.

Schär, C., and N. Kröner, 2017: Sequential factor separation for the analysis of weather and climate model results. J. Atmos. Sci., 74, 1471-1484, https://doi.org/10.1175/JAS-D-16-0284.1.

, C. Frei, D. Lüthi, and H. C. Davies, 1996: Surrogate climatechange scenarios for regional climate models. Geophys. Res. Lett., 23, 669-672, https://doi.org/10.1029/96GL00265.

, P. L. Vidale, D. Lüthi, C. Frei, C. Häberli, M. A. Liniger, and C. Appenzeller, 2004: The role of increasing temperature variability in European summer heatwaves. Nature, 427, 332336, https://doi.org/10.1038/nature02300.

Scheff, J., and D. Frierson, 2012: Twenty-first-century multimodel subtropical precipitation declines are mostly midlatitude shifts. J. Climate, 25, 4330-4347, https://doi.org/10.1175/ JCLI-D-11-00393.1.

Schmidt, D. F., and K. M. Grise, 2017: The response of local precipitation and sea level pressure to Hadley cell expansion. Geophys. Res. Lett., 44, 10 573-10 582, https://doi.org/10.1002/ 2017GL075380.

Schneider, T., 2007: The thermal stratification of the extratropical troposphere. The Global Circulation of the Atmosphere, T. Schneider and A. H. Sobel, Eds., Princeton University Press, 47-77.

Seager, R., H. Liu, N. Henderson, I. Simpson, C. Kelley, T. Shaw, Y. Kushnir, and M. Ting, 2014: Causes of increasing aridification of the Mediterranean region in response to rising greenhouse gases. J. Climate, 27, 4655-4676, https://doi.org/ 10.1175/JCLI-D-13-00446.1.

Seneviratne, S. I., T. Corti, E. L. Davin, M. Hirschi, E. B. Jaeger, I. Lehner, B. Orlowsky, and A. J. Teuling, 2010: Investigating soil moisture-climate interactions in a changing climate: A 
review. Earth-Sci. Rev., 99, 125-161, https://doi.org/10.1016/ j.earscirev.2010.02.004.

Sherwood, S., and Q. Fu, 2014: A drier future? Science, 343, 737739, https://doi.org/10.1126/science.1247620.

Singh, I., F. Dominguez, E. Demaria, and J. Walter, 2018: Extreme landfalling atmospheric river events in Arizona: Possible future changes. J. Geophys. Res. Atmos., 123, 7076-7097, https://doi.org/10.1029/2017JD027866.

Steppeler, J., G. Doms, U. Schättler, H. W. Bitzer, A. Gassmann, U. Damrath, and G. Gregoric, 2003: Meso-gamma scale forecasts using the nonhydrostatic model LM. Meteor. Atmos. Phys., 82, 75-96, https://doi.org/10.1007/s00703-001-0592-9.

Stevens, B., and Coauthors, 2013: Atmospheric component of the MPI-M Earth System Model: ECHAM6.J. Adv. Model. Earth Syst., 5, 146-172, https://doi.org/10.1002/jame.20015.

Stocker, T., and Coauthors, 2013: Technical summary. Climate Change 2013: The Physical Science Basis, T. F. Stocker et al., Eds., Cambridge University Press, 33-115, http://www.ipcc.ch/ pdf/assessment-report/ar5/wg1/WG1AR5_TS_FINAL.pdf.

Studholme, J., and S. Gulev, 2018: Concurrent changes to Hadley circulation and the meridional distribution of tropical cyclones. J. Climate, 31, 4367-4389, https://doi.org/10.1175/ JCLI-D-17-0852.1.
Tanré, D., J. Geleyn, and J. Slingo, 1984: First results of the introduction of an advanced aerosol-radiation interaction in ECMWF low resolution global model. Aerosols and Their Climatic Effects, H. Gerber and A. Deepak, Eds., Deepak Publishing, 133-177.

Ulbrich, U., W. May, L. Li, P. Lionello, J. G. Pinto, and S. Somot, 2006: The Mediterranean climate change under global warming. Developments in Earth and Environmental Sciences, P. Lionello, P. Malanotte-Rizzoli, and R. Boscolo, Eds., Vol. 4, Elsevier, 399-415, https://doi.org/10.1016/ S1571-9197(06)80011-X.

Voldoire, A., and Coauthors, 2013: The CNRM-CM5.1 global climate model: Description and basic evaluation. Climate Dyn., 40, 2091-2121, https://doi.org/10.1007/s00382-011-1259-y.

Yoshikane, T., F. Kimura, H. Kawase, and T. Nozawa, 2012: Verification of the performance of the pseudo-globalwarming method for future climate changes during June in East Asia. SOLA, 8, 133-136, https://doi.org/10.2151/ sola.2012-033.

Zhang, G., and Z. Wang, 2013: Interannual variability of the Atlantic Hadley circulation in boreal summer and its impacts on tropical cyclone activity. J. Climate, 26, 8529-8544, https:// doi.org/10.1175/JCLI-D-12-00802.1. 